This manuscript has been accepted for publication in Research Policy.

Please do not distribute or cite it without first contacting the authors.

\title{
Exaptation in a digital innovation ecosystem: the disruptive impacts of 3D printing
}

\author{
Ahmad Beltagui ${ }^{1}$, Ainurul Rosli² and Marina Candi ${ }^{3,4}$ \\ ${ }^{1}$ Operations and Information Management Dept., Aston Business School, Aston \\ Triangle, Birmingham, B4 7ET, United Kingdom, a.beltagui@aston.ac.uk \\ ${ }^{2}$ Brunel Business School, Brunel University London, Kingston Lane, Uxbridge, UB8 \\ 3PH United Kingdom, ainurul.rosli@brunel.ac.uk \\ ${ }^{3}$ Center for Research on Innovation and Entrepreneurship, Reykjavik University \\ School of Business, Mentavegur 1, 101 Reykjavik, Iceland, marina@ru.is \\ ${ }^{4}$ University of Edinburgh Business School, Entrepreneurship and Innovation Group, \\ 29 Buccleuch Place, Edinburgh, EH8 9JS, United Kingdom marina.candi@ed.ac.uk
}

\begin{abstract}
This research investigates disruptive innovation through the under-explored relationship between two ecological concepts, exaptation and ecosystems. Exaptation-driven innovation involves exploiting unintended latent functions of pre-existing technologies. Digital innovation ecosystems account for industry-spanning co-operative and competitive dynamics among firms related to innovations that combine physical and digital elements, such as 3D printing. In this work the evolution of the $3 \mathrm{D}$ printing ecosystem is traced over four decades, from the first patents—presented as exaptation-driven innovations - to the present threat of disruption to established manufacturing. Through a longitudinal narrative study of the formation and growth of this ecosystem, a four-phase process model is developed. This addresses gaps in the exaptation and disruptive innovation literatures with respect to innovation ecosystems. The implications for theory are that disruption requires an appropriate supporting ecosystem, but ecosystems take on a life of their own, so cultivating a healthy ecosystem means sowing the seeds of disruption within that ecosystem. For practice, this research highlights the managerial challenges of predicting disruption by exaptation-driven innovations and the constant competition for niches within ecosystems. For policy, it outlines implications concerning how best to support new innovation ecosystems and cultivate exaptation opportunities.
\end{abstract}

Keywords: Exaptation; Disruption; Ecosystem; 3D printing; Digital; Modularity

Classifications: L600 Industry Studies: Manufacturing: General; O310 Innovation and Invention: Processes and Incentives 


\section{Introduction}

The concept of disruptive innovation describes how a new technology alters a performance improvement trajectory or redefines how performance is understood. The phenomenon has been studied in numerous contexts, for example, in computer storage, where market leadership changed over successive generations of disk drives, despite the leader in each generation appearing inferior to its predecessor (Christensen, 1997). Research shows that disruptive innovations simultaneously disrupt some incumbents while enhancing the positions of others (Ho and Lee, 2015). Additionally, some incumbents successfully respond to potential disruptions (Ansari \& Krop, 2012) by adapting their business models (Cozzolino et al., 2018), by extending the current generation of technology (Adner \& Kapoor, 2016) or even by cooperating with disruptors (Ansari et al., 2016). To better understand the heterogeneous outcomes of potentially disruptive innovations, it is helpful to consider innovation ecosystems. Ecosystems are complex systems consisting of actors that are inter-dependent, co-evolving and in possession of agency (Choi et al., 2001). Ecosystems are self-resembling (Sahal, 1981), meaning that the system at a high-level, resembles the structure of sub-systems and components (Baldwin and Clark, 2000; Fixson and Park, 2008). This characteristic means that the modularity of technological artifacts is reflected in the structure of the ecosystem, since the producers of modules are arranged hierarchically in supply chain tiers resembling the artifact's modular hierarchy. Any technology can be viewed as a system of modular components (Baldwin and Clark, 2000). These components may be designed to perform a function in the artifact, but artifacts regularly re-use components that were initially designed for other functions (Arthur, 2009). As the technology grows in scale and complexity - i.e. as improvements enhance its performance its complexity and number of components increase, making it difficult for a single organization to control (Sahal, 1981, Baldwin and Clark, 2000). A system of interdependent organizations - an innovation ecosystem - becomes necessary to develop and combine the modules, leading to a complex, hierarchical and self-organizing structure that resembles a biological ecosystem (Iansiti and Levien, 2004).

Innovation ecosystems consist of customers, suppliers and complementors that co-operate and compete in search of survival and dominance (Moore, 1993). Substitution occurs when one actor expands its niche, to take over the roles of others (Sahal, 1981). Shimano combined six components into a bicycle drivechain unit, thereby taking market share away from previous market leaders (Fixson and Park, 2008). And 
Intel and Microsoft went from being suppliers to IBM, to the most important actors in the Personal Computer (PC) ecosystem as the relative importance of different modules changed (Fine, 1998). Substitution may also result when new entrants replace a process or technology - as when Apple introduced a touch-screen phone, thereby disrupting market leading cell-phone producers such as Nokia. We propose a distinction between internal disruption and external disruption. Internal disruption refers to competition for niches within an ecosystem, illustrated by the Shimano and IBM examples above, while external disruption refers to a disruptive innovation introduced by an actor external to an ecosystem, such as Apple's entry into the cell-phone ecosystem.

Innovations increasingly combine digital information processing with physical and mechanical components to create complex and novel functionality (Candi and Beltagui, 2019). Producing these innovations relies on complex, co-operative interconnections that cut across hardware and software industry boundaries, often in unpredictable ways (Moore, 1993; Iansiti and Levien, 2004; Adner, 2017). For example, automobile producers, which have become used to operating within a familiar ecosystem of producers and suppliers, face disruption from firms external to their ecosystem that develop autonomous vehicles, by co-opting digital technologies and leveraging digital ecosystem resources. The Global Positioning System that was developed for weapons guidance, gained commercial use in consumer smartphones, generating geographic data that can now be used to guide autonomous vehicles. This means that firms in the car industry, such as Audi and BMW, now face disruption from Google and Apple (The Economist, 2015), which capitalize on unintended functions of digital technologies. Figure 1 illustrates the complexity and modularity that define ecosystems and give rise to competition and disruption. 
Figure 1 - Illustration of disruptive innovation through exaptation and ecosystem building. Ecosystems consist of multiple firms that create modules of products. Firms may supply multiple modules, including to competing firms and may operate in multiple ecosystems.
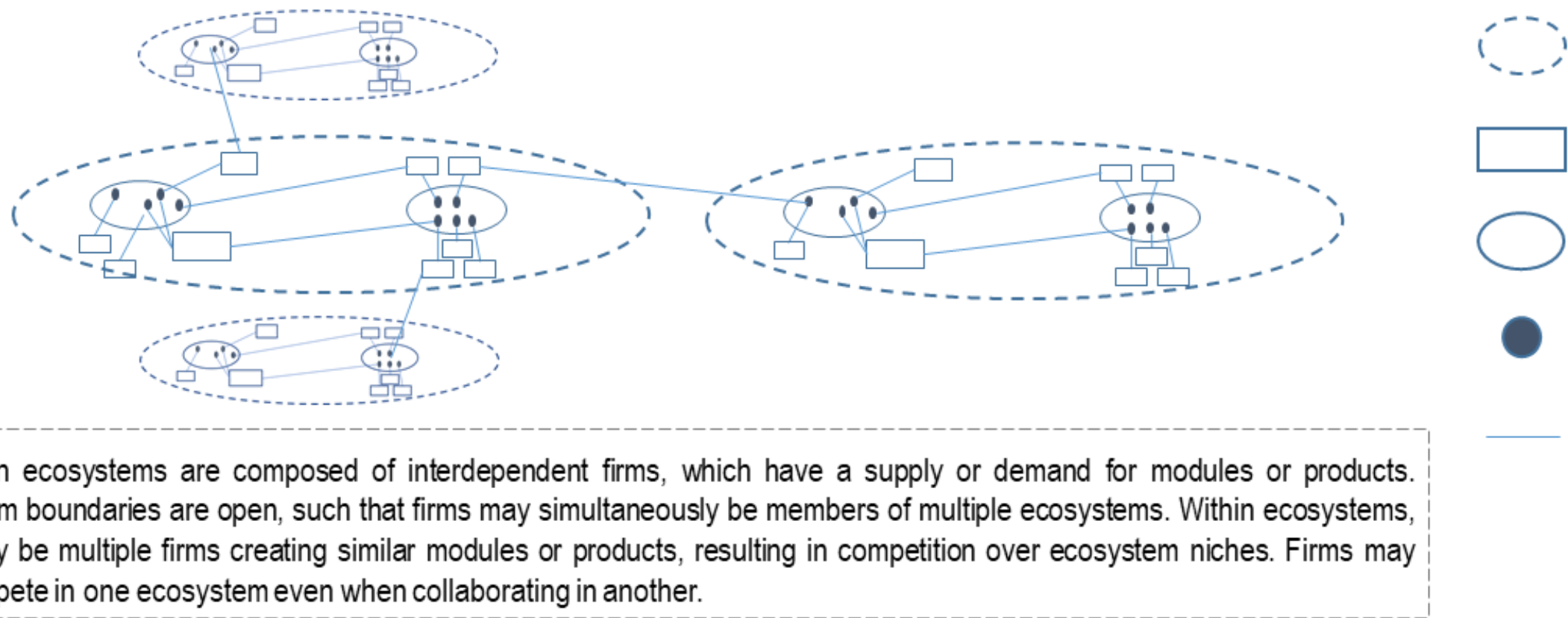

ecosystem

firm

product

module

link between firm and product/module

Innovation ecosystems are composed of interdependent firms, which have a supply or demand for modules or products Ecosystem boundaries are open, such that firms may simultaneously be members of multiple ecosystems. Within ecosystems there may be multiple firms creating similar modules or products, resulting in competition over ecosystem niches. Firms may thus compete in one ecosystem even when collaborating in another. 
The purpose of this research is to understand the mechanisms by which disruption takes place in digital innovation ecosystems. It seeks to understand how these ecosystems form, grow and disrupt. A promising lens, which can shed light on these questions is that of exaptation. Exaptation is a term used by evolutionary biologists to describe features that are co-opted for alternative functions (Gould and Vrba, 1982), for example dinosaur feathers that evolved for temperature regulation and later found a new function when their owners evolved the ability to fly. Drawing from Mastrogiorgio and Gilsing (2016) and Andriani et al. (2017), exaptation-driven innovation is the exploitation of latent functionality in existing artifacts for new contexts. Both a functional shift and non-anticipation, or serendipity, are required for classification as exaptation (Mastrogiorgio and Gilsing, 2016). For example, several examples of pharmaceuticals with unexpected side-effects - i.e. latent functionality - have led to new market opportunities (Andriani et al., 2017). Given such market opportunities, exaptation offers a route to innovation by allowing an artifact or one of its modules to be co-opted for a new function, potentially disrupting firms whose offerings previously satisfied that function (Garud et al., 2016). This often comes about through serendipitous discovery (Garud et al., 2018), for example, when a module of a radar system was discovered to generate sufficient heat to cook food (Andriani and Carignani, 2014). The specific module was isolated, combined with other components and brought to market several years later as the microwave oven. This innovation can be viewed as disruptive, for example, to fast-food restaurants facing a new competitor for customers seeking quick, convenient food. It can also be seen as the foundation for a new ecosystem, which is subsequently joined by actors such as producers of ready-meals or microwavefriendly cooking utensils.

The literature on disruption tends to focus on established ecosystems, such as that of semiconductor technologies, over several generations (Adner and Kapoor, 2016). While disruption may create uncharted markets and form new innovation ecosystems, little is known about how such ecosystems form and what role exaptation can play in them (Bonifati, 2010; Ching, 2016). To address this gap, we examine the ecosystem that has formed around three-dimensional printing (3DP) - a digital innovation. We use the term 3DP to refer to additive manufacturing technologies that create physical objects in layers, under computer control, directly from digital design models (Petrovic et al., 2011; USPTO, 2017; Candi and Beltagui, 2019). The combination of mechanical components such as motors, software such as Computer 
Aided Design (CAD) tools, advanced materials such as liquid polymers and metal powders, and services such as direct manufacturing, leads to the recognition of an ecosystem of actors and technologies (Piller et al., 2015). The ecosystem's origins can be traced to the patents for exaptation-driven inventions, granted in 1986 and 1992, respectively (Appendix 1). In the years following the introduction of these inventions, the ecosystem has grown steadily, capturing the public imagination amid claims of a new industrial revolution (Barnatt, 2016; Rüßmann et al., 2015). Debate centers on whether 3DP is currently, or could shortly become, disruptive to incumbents in established sectors, for example, the rapid adoption of 3DP by major hearing aid producers and the subsequent impact on market position are discussed by D’Aveni (2015) and by Sandström (2016). Using a narrative research approach, we develop a four-phase process model describing exaptation-driven ecosystem formation, ecosystem growth driven by cooperation with new ecosystem entrants, internal disruption caused by changing roles or exaptation-driven entry, and finally external disruption—whereby the 3DP ecosystem can potentially have a disruptive effect on established ecosystems. We map these phases over four decades, and present evidence from a range of sources to create a narrative process model linking exaptation to ecosystem formation, growth and disruption (Pentland, 1999; Ansari et al., 2016).

This research makes three important contributions to literature. First, it demonstrates how exaptationdriven innovation can form the foundation for ecosystem construction as well as niche-construction (Andriani and Carignani, 2014). Second, it demonstrates how ecosystem growth creates niches for the entry of actors through further exaptation and identifies the presence of resulting internal distuption. Thirdly, it provides evidence that ecosystem health and evolution are pre-requisites for external disruption. We highlight challenges for managers, which include building an ecosystem by encouraging the entry of supporting firms while maintaining a position by controlling a niche or sustaining leadership. We also identify challenges for policymakers around the need to support ecosystems by creating the appropriate conditions for exaptation.

\section{Literature review}

The disruptive innovation model describes how new entrants overturn the dominance of market leaders, despite possessing inferior technological resources (Christensen, 1997). Much of the discourse on disruptive innovation is output-centric (Ho and Lee, 2015), focuses on particular cases and attempts to 
explain when and how disruptive innovation occurred (e.g., Keller and Hüsig, 2009; Snihur et al., 2018). This research extends our understanding of disruption by drawing on two concepts from biologyecosystems and exaptation — to investigate how new digital innovations generate ecosystems and create opportunities for disruption. Previous research has primarily focused on studying established ecosystems (Adner and Kapoor, 2010; 2016), examining how new entrants create disruption within such ecosystems (Ansari et al., 2016) or how incumbents respond (Ansari and Krop, 2012). In contrast, the formation of ecosystems has drawn limited attention (Dedehayir et al., 2016). How new entrants contribute to ecosystem growth and disruption is under-investigated (Autio et al., 2018), and innovation in general (Nambisan and Baron, 2013), and exaptation-driven innovation in particular are ill understood in ecosystems.

\subsection{Evolutionary metaphors for innovation}

Evolutionary theories of technology suggest that innovation resembles the evolution of species over time in a process of descent with modification (Darwin, 1859). For example, mapping the historical development of weapons and tools shows how an original design is modified to perform a specific function, resulting in a linear evolution and allowing the heritage of an innovation to be traced back over generations (Basalla, 1989). Arthur (2009) argues that, at a modular level, every technology is a combination of pre-existing modules, components and subsystems, which are "cobbled together" (p.48), but then subsequently refined over time to better suit its purpose. Most radical innovations or new technologies follow a similar evolutionary pattern. As the technology matures, the supporting systems around it grow and create fertile ground for disruptions (Iansiti and Levien, 2004) and, thus, an ecosystem is born.

Carignani et al. (2019) propose a different perspective by introducing horizontal gene transfer (HGT) as a metaphor. HGT is "the non-genealogical transfer of genetic material from one organism to another" (Goldenfield and Woese, 2007, p.369). It suggests that characteristics can be passed horizontally among single-celled organisms, such as when antibiotic resistance is transferred between bacteria, not only vertically as in Darwinian evolution. Carignani et al. (2019) use this perspective to explain the development of the jet engine by the transfer of modules (compressor, combustor and turbine) from other products into the turbojet. Subsequent variants, such as the turboprop and turbofan can be traced 
back to the turbojet, a common ancestor, such that these innovations emerged initially through horizontal transfer and then through vertical refinement. Central to this process is the notion that preadapted modules are selected to occupy niches in a product architecture. To explain these terms, the following sections summarize the literature on ecosystems, which contain niches that are organized in a similar structure to the product architecture, and exaptation — which relates to the use of preadapted modules for alternative purposes. Before discussing ecosystems and exaptation, however, we discuss the underlying mechanism connecting the two, namely modularity (Sahal, 1981; Arthur, 2009, Andriani and Carignani, 2014).

\subsection{Modularity}

Any artifact can be regarded as a modular system (Baldwin and Clark, 2000), meaning that innovation focuses on improving either or both, the architecture of the system or the modules it is comprised of. Baldwin and Clark (2000) identify a set of six modular operators as a complete set of actions that designers use on any modular design—splitting a design into multiple modules, substituting one module for another, angmenting the system through addition of a module, excluding a module from the system, inverting to change the architecture, and porting a module to another system. Fixson and Park (2008) extend this discussion by adding a seventh operator, namely integrating multiple modules into a single design. The effect of integrating modules is to consolidate the supply chain so that previous providers of modules may not be required.

Innovation tends to focus initially on building an entire architecture rather than specific modules. Initial success creates a platform for other firms to create both competing and complementary innovations (Gawer and Cusumano, 2014). As demand for the innovation grows, competition increases, quite possibly bringing on a battle to define standards and establish a dominant design (Suarez and Utterback, 1995). When the complexity of the artifact becomes too great for a single firm to manage, others may focus on modular innovations (Baldwin and Clark, 2000). Specialized firms enter into specific stages of production, whereas less specialized firms exit when they are unable to compete effectively (Kapoor, 2013). As the various modules evolve, they become strongly functionally interdependent in a manner that makes customer demand dependent on the entire system, with little demand for modules in isolation (Gawer and Henderson, 2007). In this way, modularization of artifacts is typically accompanied by disaggregation 
as specializations are accommodated. An exception that proves the rule is the integration of previously modularized bicycle drive trains by Shimano (Fixson and Park, 2008). This represents innovation at the system architecture level, which was competence-destroying, transforming a previously competitive market into a near monopoly by lessening the need for specialized capabilities. However, innovations do not always disrupt an entire industry. The impact of digital photography on the incumbents in the camera and film processing industries reveals that different modules, and the specialized firms associated with them, face differing impacts (Ho \& Lee, 2015). The introduction of digital cameras made film processing capabilities redundant, disrupting firms such as Eastman Kodak, while arguably leaving producers of camera lenses in a better position (Lucas \& Goh, 2009). From these examples, we can see that ecosystems are modular hierarchical architectures, which resemble the architecture of artifacts, comprising firms that create modules or assemble architectures. We also see that new technologies disrupt actors by displacing modules and the actors that create them.

\subsection{Innovation Ecosystems}

The academic discourse is moving away from an output-centric view of industries, e.g., the auto industry or the cochlear ear implant industry (Aldrich and Fiol, 1994), and towards a focus on ecosystems, which capture the interactions between a variety of actors and incorporate both supply and demand sides (Moore, 1993, 1996; Iansiti and Levien, 2004; Autio and Thomas, 2014; Snihur et al., 2018). Ecosystems are complex adaptive systems (Choi et al., 2001) characterized by the interplay among the behaviors of individual actors and those of the whole system across indeterminate boundaries. They are often defined by a focal firm or platform and incorporate both value creation and value appropriation mechanisms (Autio and Thomas, 2014). As the relationships among firms and their business partners have become more crucial for business success, they have become more complex. This requires alignment among a multilateral set of partners (Adner, 2017) that can influence the co-evolution of the ecosystem and individual firms (Hannan and Freeman, 1977). This evolution cannot be fully understood by considering only individual firms, technologies or artifacts. Hence, understanding how disruption takes shape requires an understanding of the relationships that bind actors in an ecosystem and how these are formed.

Ecosystems consist of a series of niches that are filled by actors, e.g. species in a biological ecosystem's food-chain or firms in an innovation ecosystem. In the latter, ecosystem leaders create opportunities for 
others (Iansiti and Levien, 2004; Gawer and Cusumano, 2014) and profit by providing goods and services while contributing to the overall health and diversity of the ecosystem (Nambisan, 2017). Niches are occupied by firms that seek to satisfy both their own and the ecosystem's objectives (Nambisan and Baron, 2013; Dedehayir et al., 2016). As with biological ecosystems, new entrants with specialized capabilities and features may compete to fill these niches. Ecosystem entrants may emerge and evolve from different starting points. For example, studies of biotechnology ecosystems show a variety of entry points through which firms use their capabilities and partner with other firms to target appropriate market opportunities (Lee and Malerba, 2017). Their entry brings about competition for incumbents occupying niches in the ecosystem; meanwhile, diversity and competition for niches are considered indicators of ecosystem health (Levin, 1998; Li and Garnsey, 2014).

Ecosystems that facilitate ease of entry allow competition and the possibility of disruption. Firms survive in these ecosystems by facing disruption and adapting to continual threats from new entrants (Moore, 1996; Ansari and Krop, 2012). For example, some trees evolve fire-resistant seeds as a consequence of surviving fires (Levin, 1998), while others do not. Similarly, firms update their capabilities and develop new business models in response to competition (Teece, 2010). Diversity, complexity and pathdependence can mean that ecosystems and their actors may respond differently to external stimuli. Some firms in an ecosystem will survive and thrive, whereas others may be disrupted by competition. Moore (1993) argues that biological ecosystems where new entrants are rare, such as islands, do not prepare their inhabitants to resist competition and the same could be said of industries or countries that facilitate monopolies. Just as the introduction of grey squirrels into the United Kingdom has had a negative effect on numbers of red squirrels, the emergence of international competition has had a negative effect on businesses in many countries.

The fate of individual firms is at least in part determined by the actions of the ecosystem (Hannan and Freeman, 1984), which effectively has a life of its own. Changes in one part of an ecosystem can have unexpectedly disruptive impacts in others. For example, the importance of sea otters was recognized when oil spills affected their numbers (Estes and Palmisano, 1974). Sea otters eat crabs, which eat sea slugs, which eat algae, which otherwise prevents seagrass from receiving sunlight. Similarly, the introduction of wolves to Yellowstone National Park has caused elk to keep moving in search of food, 
preventing over-grazing in the same spots and helping to allow trees to thrive. As these examples demonstrate, a new entrant may threaten a particular species that it competes with or preys on but contributes to a healthy ecosystem's ability to maintain equilibrium through self-regulation. The literature identifies how ecosystem leaders, in seeking to cultivate a healthy ecosystem, may face disruption. This is particularly notable in the PC ecosystem, where IBM's dominant position became an almost irrelevant one. Having dominated the mainframe computer industry, IBM did not initially engage with the PC ecosystem led by individuals such as Apple founders Steve Wozniak and Steve Jobs. While small firms in this ecosystem were initially dismissed as hobbyists (much like 3DP startups more recently), once the business potential of PCs and the software they developed became evident, this ecosystem and the firms within it, began to represent a threat (Wozniak and Smith, 2006). IBM only entered the ecosystem when the demand for PCs had become large enough that the scale of its production infrastructure allowed it to take a leading role quickly (Moore, 1993). However, IBM failed to manage its position successfully, allowing its suppliers, Microsoft and Intel, to command more important roles in the ecosystem, and ultimately push it out of PC production. "Intel inside" became more important than IBM on the box (Fine, 1998). Examples such as this demonstrate that ecosystem leadership is fluid.

\subsection{Exaptation}

To understand how ecosystems come into being and evolve, we now turn our focus to exaptation. The term exaptation was proposed by evolutionary biologists as a complement to adaptation (Gould and Vrba, 1982). Whereas adaptation refers to features that develop for a specific function, such as larger lungs among Andean mountain people, exaptation refers to features that are later found to be useful for unintended functions (Mastrogiorgio and Gilsing, 2016; Andriani and Cattani, 2016). Innovation examples include the repurposing of specialist glass production technology for producing optical fibers (Cattani, 2005), compact discs, an audio recording technology, for data storage (Dew, 2007) and laser technologies for applications from barcode scanners to surgery (Bonifati, 2010). In each of these examples, there is a possibility to disrupt incumbents and the technologies previously used for these applications. While the literature provides explanations of how exaptation leads to innovation, the disruptive potential of exaptation has not been sufficiently explored. 
Several approaches have been used to delineate types of exaptation. Considering the frequency of exaptation in pharmaceutical innovation, Andriani et al. (2017) devised a measure of the functional distance between an originally approved use and an emergent one. This is particularly relevant in complex systems, in which the potential new uses for an innovation are not fully known (Andriani and Cohen, 2013). In such contexts, exaptation plays an important but often overlooked function in the evolution of technology and the creation of new markets (Dew and Sarasvathy, 2016). In the innovation literature, exaptation has been classified according to the level of effort required to convert from the original to a new function. This involves internal and external search processes (Katila and Ahuja, 2002), which may cross ecosystem boundaries. Exaptation frequently involves an element of serendipity (Garud et al., 2018); an interaction between an artifact and a context, often without a specific objective, may bring to light alternative functions and allow innovations to emerge. Following Baldwin and Clark's (2000) approach to decomposing artifacts into modules, Andriani and Carignani (2014) distinguish between the change of function of the whole artifact, or of its modules. The former requires minimal effort, e.g. the tuberculosis drug, Marsilid, was repurposed through marketing as an anti-depressant. Meanwhile, changing the function of modules normally requires niche construction (Andriani and Cohen, 2013), a substantial effort to build a new architecture around an exapted module. For example, several decades of development separated the discovery of an alternative function for the magnetron, a radar component, before it came to market in the microwave oven (Andriani and Carignani, 2014; Garud et al., 2016). These examples focus on changes in the function of artifacts. However, ecosystems are largely missing from the exaptation literature, which is an important omission.

\subsection{An exaptation-driven model of ecosystem formation and disruption}

Ecosystems are hierarchical and can be decomposed into sub-systems, which co-evolve (Choi et al., 2001). At a modular level, exaptation entails building a new structure around a module taken from an existing technology (Andriani and Carignani, 2014). A possibility that has not previously been expressed in the exaptation literature is that a new ecosystem may form around the exaptation-driven innovation. A case in point is that of the Gutenberg printing press (Andriani and Carignani, 2014). In this case, Gutenberg co-opted the functionality of a press used for squeezing juice from grapes to make wine. He applied the idea of pressing against a flat surface to printing, thus laying the foundation for the paper 
publication ecosystem that is still in force. Thus, Gutenberg's exaptation formed the foundation for an ecosystem.

As discussed above, new technologies can emerge from combinations of previously existing modules (Arthur, 2009; Andriani and Carignani, 2014), which are then refined over time, evolving to suit a function to which they are applied (Basalla, 1989). This evolution is accompanied by a growth in the supporting ecosystem (Sahal, 1981; Baldwin and Clark, 2000) and the configuration of the technology is subject to experimentation and variation until there is agreement on a best approach (Suarez and Utterback, 1995). Drawing from theories of disruptive innovation, ecosystems, exaptation and modularity, we can model the birth and growth of an innovation ecosystem and how this growth facilitates disruption within the ecosystem and then in other ecosystems in four phases as shown in Figure 2. 
Figure 2-A dynamic model of ecosystem formation and disruption, following modular exaptation.

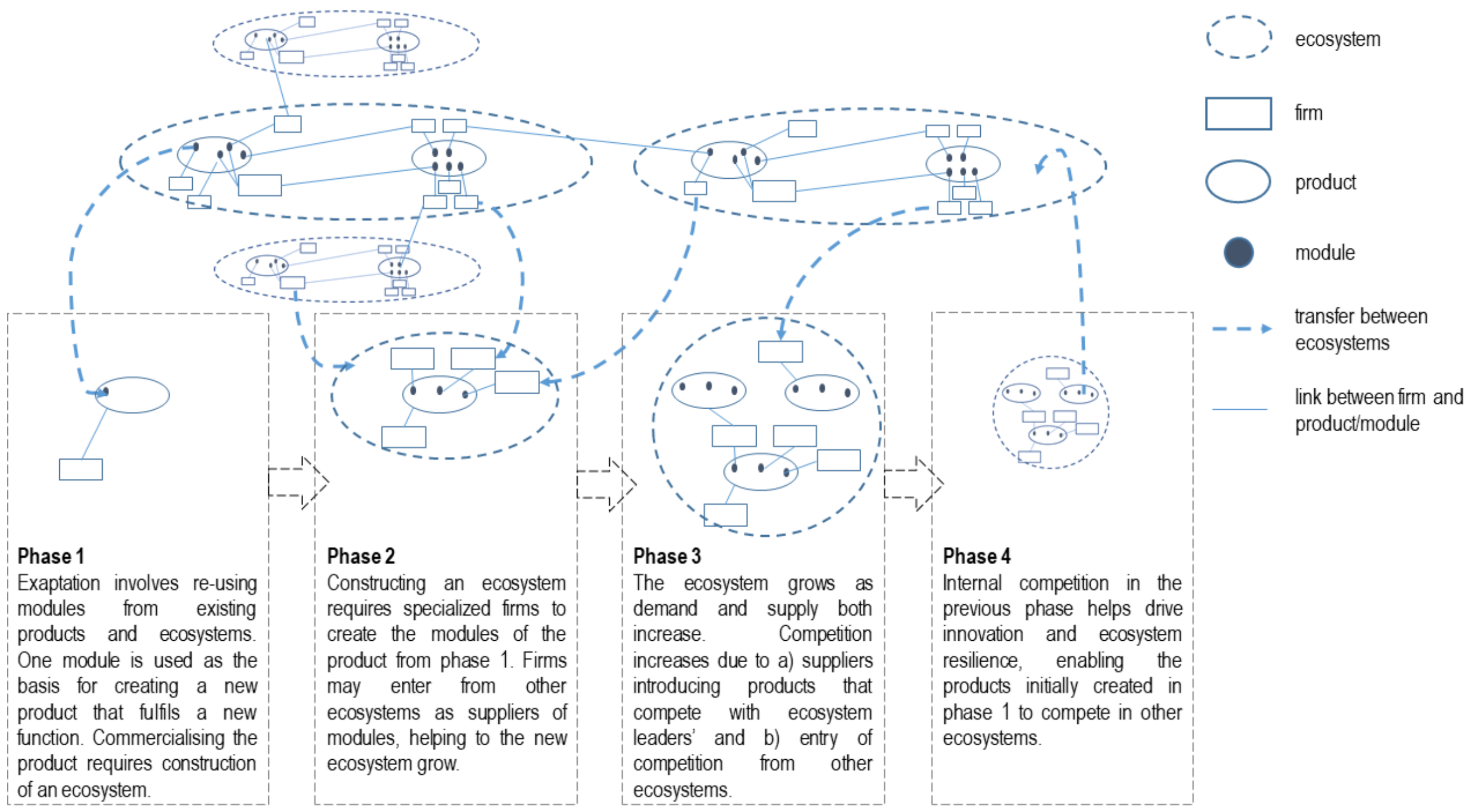


Ecosystems are hierarchically composed in a structure that resembles the composition of modules in a product architecture (Baldwin and Clark, 2000; Fixson and Park, 2008; Arthur, 2009). Thus, ecosystem roles describe the relationships between firms such as suppliers and producers (Dedehayir et al., 2019) and the modules and architectures these firms are responsible for creating (see figure 1). Modular exaptation, therefore, involves a module of the architecture being ported into a new architecture by a firm that also moves from its original ecosystem into a new, unpopulated ecosystem (phase 1 in Figure 1). Andriani and Carignani (2014) demonstrate that considerable effort is required to turn an exapted module into a marketable product. They suggest that constructing an architecture around the exapted module requires specialized capabilities, which means innovation may be decentralized to firms possessing these capabilities. As a result, firms migrate into the new ecosystem from their original ecosystems (phase 2), as the ecosystem leader cannot expect to possess all of the capabilities required to produce the entire architecture (Baldwin and Clark, 2009). Every technology exploits one or more phenomena to fulfil a function (Arthur, 2009), but changing a module means that a phenomenon and the capabilities required to exploit it may change. For example, for digital cameras, the change from chemical to digital technology means a change in the firms that fill a particular niche, even as other modules and firms, such as lens manufacturers, retain their places (Lucas and Goh, 2009). While a linear evolutionary development can be expected as the exapted innovation continues to be modified and improved, the need to access capabilities external to the nascent ecosystem draws on horizontal transfer of modules (Carignani et al., 2019). As a result, competition within the ecosystem intensifies as firms that have entered at different times compete to define the standards (Suarez and Utterback, 1995). Simultaneously, the competition for ecosystem niches and dominance sees suppliers and customers beginning to compete, just as IBM faced disruption from its suppliers (Moore, 1993; Fine, 2000). The health of the ecosystem as a whole is aided by openness to new entrants, which brings with it disruption to ecosystem members and a requirement for resilience to survive (phase 3). Mapping this evolution against the typical path of disruptive innovation (Christensen, 1997), we can surmise that the competition inside the ecosystem also leads to performance improvements in the technologies employed. As new firms enter and compete for ecosystem niches, they also transfer their technologies to the new application (Carignani et al., 2019) and compete to define 
standards (Suarez and Utterback, 1995). Finally, the performance improvements may enable a technology to realize its disruptive potential in other ecosystems (phase 4).

\section{Research Method}

\subsection{Research Setting}

The 3DP ecosystem was examined to investigate the interrelationships among exaptation, innovation ecosystems and disruption. This ecosystem has grown slowly over several decades, around inventions that we identify as exaptation-driven innovations. Subsequent growth has been rapid. Global revenues for 3DP products and services grew from approximately $\$ 1 \mathrm{bn}$ in 2009 to over $\$ 2 \mathrm{bn}$ in 2012 , to over $\$ 5 \mathrm{bn}$ in 2015, with compound annual growth over 30\% over most of this period (Wohlers, 2016). 3D Systems and Stratasys combined account for over a fifth of the total. By comparison, the total sales revenues of firms now entering the ecosystem, such as Ricoh Company Ltd and its subsidiaries (\$18.6bn), HP Inc. (\$103.4bn) and General Electric Co. $(\$ 115.9 \mathrm{bn})$, illustrate the strategic value these firms see in 3DP. 3DP technologies are reaching sufficient maturity that the 3DP ecosystem could disrupt more established manufacturing technologies, leading such firms to respond by leveraging their research, production and marketing resources similar to IBM's entry into the PC ecosystem.

Studying this ecosystem at present is relevant for several reasons. Firstly, its origins can be traced back to the original patent for stereolithography, granted in 1986 (Appendix 1), allowing a reasonable investigation of its formation. This contrasts with previous studies that examine disruption within established ecosystems (e.g. Christensen, 1997; Adner and Kapoor, 2016; Ansari et al., 2016). Secondly, the expiry of the first patents has contributed to a growth in interest, ecosystem entry and disruptive potential. This allows investigation of how exaptation facilitates ecosystem entry as well as revealing the links between exaptation and disruption. Thirdly, the co-existence of vastly different processes and applications in the same space provides an opportunity to study a diverse ecosystem that may later disperse into more specialized sub-systems. For example, production of laser sintered aerospace components from titanium powder is vastly different from the use of desktop machines for prototyping consumer products, yet 3DP is used as a shorthand for both. Finally, by combining software with mechanical and chemical processes, this is a genuinely diverse ecosystem (Petrovic et al., 2011; Piller et al., 2015) and provides a template for understanding future digital technologies. 
This research exploits the timely opportunity to examine the 3DP ecosystem while it remains diverse, experiences rapid growth and sees relatively small firms competing for future leadership. A narrative approach is used to examine the formation and growth of the 3DP ecosystem and derive findings related to exaptation and disruption.

\subsection{Data Sources}

There is a growing trend for the use of secondary data, including from internet sources, for academic research (Kozinets, 2002). For example, Franzoni and Sauermann (2014) use examples of online projects to contribute an understanding of crowd science and its role in innovation. On the topic of 3DP, West and Kuk's (2016) study of the complementarity of openness uses a variety of sources to present a case study of how Stratasys supports open source communities to create demand for its proprietary products. In addition to secondary data from Stratasys' websites and from online communities, West and Kuk (2016) draw from the Wohlers report (Wohlers, 2016), an industry analysis that has been published annually since 1993 . We follow this approach to data collection by drawing on industry reports (Rüßmann et al., 2015; Wohlers, 2016; Müller and Karevska, 2016), academic publications (e.g. D’Aveni, 2015; West and Kuk, 2016) and books (Barnatt, 2016; Bandyopadhyay et al., 2015) as well as firm websites, press releases and news reports.

\subsection{Narrative method}

A narrative is an interpretive description of historical facts that seeks to give meaning to a series of events (Gabriel, 2000). Narrative studies are valuable for examining processes, allowing the researcher to understand events, how and why they occurred and how they lead phenomena taking shape over time (Pentland, 1999). This is because narratives are enacted and performed, meaning the telling of the story is linked to the performance of the actions (Garud et al., 2014). Researchers construct narratives by identifying a series of key events and capturing the perspectives of the actors involved to understand these actors' interpretations of the events. For example, Narayanan et al. (2009) examine the development of dynamic capabilities within two divisions of a pharmaceutical firm through the construction of group narratives, while Brown (1998) examines the tensions between stakeholders during an information system implementation project. Such studies are commonly used in innovation research to uncover the mechanisms behind historical processes and help to shape our understanding of why certain events 
happened or how to manage them in the future. The narrative approach has been widely used in exaptation research to understand the processes involved (Cattani, 2005; Andriani and Carignani, 2014). Garud et al. (2016) argue that the process of exaptation-driven innovation is itself a narrative approach, which lends support to studying the evolution involved using a narrative perspective. Most narrative studies focus on longitudinal analysis of one or two cases, aiming for depth of understanding. For example, Ansari et al.'s (2016) study of TiVo, Fixson and Park's (2008) study of Shimano, or West and Kuk's (2016) study of Makerbot and its Thingiverse platform. Other studies capture multiple cases, looking for similarities in the processes observed within these cases (e.g. Andriani and Carignani, 2014; Franzoni and Sauermann, 2014; Garud et al., 2016).

The 3DP ecosystem is the unit of analysis of the present work, and a longitudinal approach is used to study how the ecosystem has evolved. There is a particular focus on two firms, 3D Systems and Stratasys. These firms were chosen for two main reasons. Firstly, they are identified as the earliest surviving members of the 3DP ecosystem, due to their patents for Stereolithography (SLA) ${ }^{1}$ in 1986 and Fused Deposition Modelling (FDM) 2 in 1992, respectively, and are cited by most reviews of the field as the earliest commercial sellers of 3D printers (Bandyopadhay et al., 2015). The origins of what is now referred to as the 3DP ecosystem can be traced to these two firms, their founders and original patents, and they offer a valuable opportunity to examine how exaptation-driven innovations can lead to ecosystem formation. Secondly, these two firms remain the largest industrial 3D printer producers in the world by sales (Wohlers, 2016) and by market capitalization, as shown in Appendix 1. Additional firms were selected for inclusion in the narrative by identifying co-operations within the timeline shown in Figure 3 as well as analyzing current trends and market positions. Ricoh and HP are important to the narrative since both co-operated with Stratasys as well as now competing, while GE was identified through analysis 
of the ecosystem due to its acquisition of 3DP firms such as Arcam and Concept Laser (e.g., Wohlers, 2016).

\subsection{Data analysis}

Following Ansari et al. (2016), a narrative of the 3DP ecosystem was constructed based on a range of data sources. By identifying key events and dates in a timeline, we were able to search online repositories for news reports, for example relating to mergers, acquisitions, product launches or legal disputes. We made use of firms' websites, including press releases, patent and product information, annual reports and published accounts. Additionally, we were able to use publicly available videos, including interviews, television appearances and keynote speeches by executives. The authors attended industry events where the firms exhibited and promoted their offerings, while one of the authors also attended an event run for local customers and partners of one of the firms, providing insights into strategy and products. These diverse longitudinal data allowed triangulation from multiple sources (Jick, 1979). They were captured in a written narrative and a timeline of key events (Figure 3). This timeline allowed comparative analysis, from which key themes emerged and led to the identification of the phases of evolution outlined in the findings and Table 3.

We apply patent citations as one means by which to identify exaptation, demonstrating both a functional shift and an element of non-anticipation (Mastrogiorgio and Gilsing, 2016) or serendipity (Garud et al., 2018), as operationalized by Andriani et al., (2017). Patents indicate the intended function of an invention, through an assigned classification, while patent citations in different classifications indicate how technologies are applied to new functions (Mastrogiorgio and Gilsing, 2016). Patents have been used widely for studying a particular type of product, such as airbags (Fixson and Lee, 2012) or to understand how firms search for new knowledge (Katila and Ahuja, 2012) and are helpful indicators of ecosystem entry. However, measuring the distance between functions can be arbitrary without a relevant typology for understanding technology and function (Andriani et al., 2017) and delineating the boundaries of an ecosystem can be challenging. To overcome these challenges, we focus on the B33Y classification of the United States Patent and Trademark Office (USPTO), which includes "manufacturing of 3D objects by additive deposition, additive agglomeration or additive layering, e.g. by 3D printing, stereolithography or selective laser sintering" (USPTO, 2017). To consider ecosystem entry, we identify instances of exaptation by examining a firm’s 
patents cited in the B33Y classification. For example, Ricoh was granted US patent No. 8,192,9173, classified within the B33Y patent classification. This cites their own previous patent, US No.

20,080,092,3104, which was classified under B22F1 (Nanofibres or nanotubes), demonstrating their use of internal knowledge (Katila and Ahuja, 2002). This is evidence of exaptation as the patent classification identifies the intended function, and the citation in a different classification shows the identification of a previously unintended function (Mastrogiorgio and Gilsing, 2016; Andriani et al., 2017). We also take this as evidence that Ricoh operates in multiple ecosystems, including 3DP.

\section{Findings}

The timeline in Figure 3 provides an overview of the key events identified in the narrative of the 3DP ecosystem, with a focus on the original actors, Stratasys and 3D Systems. Based on an analysis of this narrative, we identified four phases in the development of the 3DP ecosystem, which are, in chronological order, the ecosystem formation —arising through exaptation, a period of ecosystem growth and subsequent phases of internal dismption and external disruption. Each of these phases is discussed below.

\footnotetext{
${ }^{3}$ Filed June 28, 2007, Granted June 5, 2012.

${ }^{4}$ Filed April 27, 2005, Granted Nov 9, 2006.
} 
Figure 3- Timeline of 3D Systems' and Stratasys' narratives

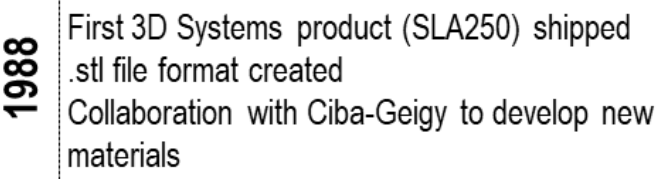

Charles Hull starts 3D Systems

Corp. and files first 3DP patent

\begin{tabular}{|c|c|c|}
\hline $\begin{array}{l}\text { Charles Hull } \\
\text { produces his first } \\
\text { 3D print - } \\
\text { a blue optometrist's } \\
\text { cup using UV } \\
\text { radiation and }\end{array}$ & 욤 & $\begin{array}{l}\text { 3D Systems' first } \\
\text { non SLA machine } \\
\text { (Actua 2100) } \\
\text { using wax and } \\
\text { inkjet print. }\end{array}$ \\
\hline
\end{tabular}

\section{D Systems}

1980 s

1990 s

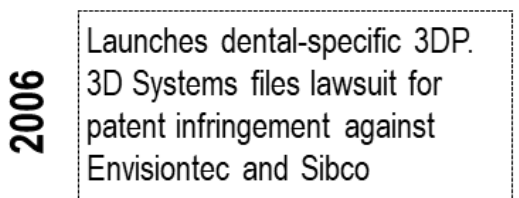

3Dproparts service launched,

\% later expanded through

acquisitions in Europe and US. Exits consumer market.

Announces industrial

manufacturing system

Launches industry specific

products for jewellery and

ก hearing aid production

$\infty$ Lawsuits filed against 3D

Systems by Tangible and

DSM.

Launches Invision Envisiontec

ॄ. printer, which jets and

ก hardens photopolymer, similar to Objet.

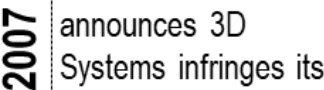

German patents.

Start of corporate acquisition program, targeting

5 over 50 software, materials and technologies firms

글 following years.

3D Systems faces antitrust investigation following acquisition of DTM (developer of Selective Laser Sintering) forcing licencing of SLA to Sony.
3DP and robotic post-

ฟ processing for volume production.

Enters consumer market with Cube printer and Cubify online platform. Files lawsuit for patent infringement

against Formlabs and Kickstarter

N 3D Systems acquires Z Corp., which developed color jet printing

$\mp$ 3D Systems floated on NYSE $\odot$ based on integrated

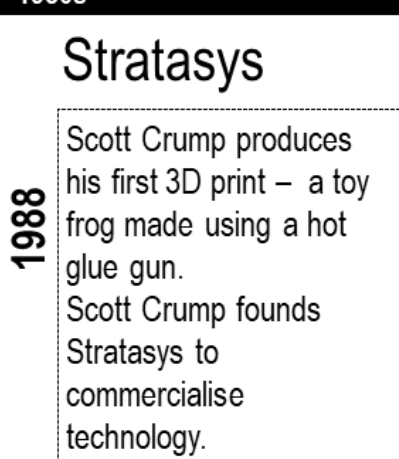

Sources: Bandyopadhyay et al., 2015; Wohlers, 2016; Barnatt, 2016 ; Company reports and press releases.

宁 2000s
Scott Crump awarded first 3DP patent: "Apparatus and method for F) creating three-dimensional objects"

First Stratasys product (3D Modeler) shipped ำ

Stratasys acquires IBM's 3DP patent infringement.

c) Launches most successful of product to date (Genisys) using technology acquired from IBM division, avoiding action over
Sets up

10. print

요 service

(RedEye

RPM).

\section{으 Agrees to produce HP \\ 음 branded machines \\ E Engages Ricoh as \\ 을 supplier of components}

Stratasys merges with

$\mp$ Objet Ltd.

Agreement with HP ends.

m Enters consumer

을 market with acquisition of Makerbot Industries 2010s

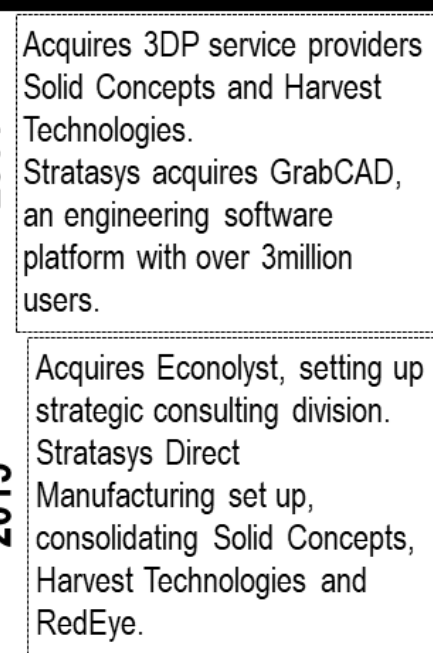




\subsection{Exaptation}

Early efforts to develop 3DP technologies can be identified in the R\&D labs of various firms in Japan and Europe. But the first patent and the first firm to commercialize 3DP can be traced to Charles "Chuck" Hull, an engineer and would-be entrepreneur, employed by a struggling firm producing liquid coatings, hardened by ultraviolet radiation on products such as furniture. Driven by frustration at the time taken for prototyping his product designs, Hull spotted a potential solution by exploiting the latent functionality of the firm's technology.

"I put two and two together, if I could cure lots of these layers, I could have a real plastic part. So that was just kind of the basic aha! And then it was all the effort to make that happen." ${ }_{5}$

Following a period of experimentation, Hull produced the first 3D print in 1983 and registered a patent in 1986 for the process of stereolithography (SLA, see Appendix 1 for the patent reference). With his employer unable to support the invention, Hull formed 3D Systems to commercialize the patent. Independently, Scott Crump developed his 3DP technology, Fused Deposition Modelling (FDM) in his home, with the purpose of creating toys for his daughter. By combining elements of a $2 \mathrm{D}$ plotter with a hot-glue gun and a combination of materials including candle-wax, he could build an object in layers. Crump started Stratasys shortly afterwards and was granted his first patent in 1989 (see Appendix 1).

Both these cases represent exaptation-driven innovation since they entail a shift in function (liquid coatings to prototyping; gluing to printing) and a serendipitous combination of pre-existing components to exploit latent functionality. Both Hull and Crump combined readily-available modules to achieve a new function. While the processes differ, at a high level they achieve a similar function, building products additively by layering, under computer control. The firms started by the two inventors served existing needs, primarily engineers' need for prototyping tools and services. However, they had little connection to existing ecosystems and can be regarded as the founders of the 3DP ecosystem.

\footnotetext{
${ }^{5}$ Interview with TCT magazine, available at https://www.youtube.com/watch?v=yQMJAg45gFE last accessed 13th June 2018
} 
Even in this early phase, enthusiasm led to optimistic, albeit vague, predictions of 3DP's disruptive potential. For example, in a 1989 interview, Hull suggested that "it does for engineering and manufacturing what the Xerox machine or the word processor or both of those do for the office environment" 6 . In the same interview, 3D Systems' CEO, Raymond Freed suggested that with "probably five or more years' hard research" it would "revolutionize" production. Exaptation can be viewed as a first important, but not sufficient, step in developing disruptive innovations, but as the story of the early days of 3DP shows, for innovations to reach their disruptive potential, a suitable ecosystem is needed. This brings us to the second phase in the development of an ecosystem - the growth of the ecosystem.

\subsection{Ecosystem Growth}

The first indication that an ecosystem is required can be seen from the development of a software standard in support of 3DP. Chuck Hull recognized that to engage designers who would benefit from 3DP, Computer Aided Design (CAD) software would need to convert digital models into an appropriate form. He developed and patented a process for file conversion, which enabled designers to print their CAD models, as well as the .stl file format, which remains the standard for 3DP. Recognizing that CAD developers would be reluctant to include support for an unknown, proprietary file format in their software, ecosystem growth was prioritized over control.

\section{'T just made the decision, let's make that public. We basically declared that we would not enforce that patent and so that} basically freed it up so that people would write to it." ,

This demonstrates that, following exaptation, an innovator may need to engage with other actors, to ensure adoption of the new technology. Standards help to enable co-operation (Suarez and Utterback, 1995), and when considering technology at a modular level, specifying a design early enables the entry of other firms into the ecosystem.

\footnotetext{
${ }^{6}$ Interview with Good Morning America, available at https://www.youtube.com/watch?v=NpRDuJ5YgoQ, last accessed 13th June, 2018

${ }^{7}$ Interview with TCT magazine, available at https://www.youtube.com/watch?v=yQMJAg45gFE last accessed 13th June 2018
} 
3D Systems and Stratasys continued to develop their core technologies, but their growth included interactions with modular innovators whose involvement expanded the ecosystem. 3D Systems partnered with other firms to develop materials. Like software standards, print materials are crucial for 3DP and demand growth so the continued development of 3DP required specialized firms with capabilities in chemical science and materials (Fixson and Park, 2008).

Additionally, 3D Systems continued to develop new 3DP technologies using other materials such as wax and metal (Wohlers, 2016). These new technologies are distinct from SLA (stereolithography) and FDM (Fused Deposition Modelling) but belong to the same ecosystem because they share modules, achieve similar functions and exploit some of the same phenomena (Arthur, 2009). 3D Systems' exploration of processes and materials brought the firm into conflict with other firms in the growing ecosystem. This included several patent infringement cases and an antitrust investigation leading to part of its operations being sold (see Figure 3). 3D Systems commenced a broad acquisition program, purchasing a variety of small firms involved in the development of materials, software and other related technologies. Scaling up from an innovation demands modular innovation, which also requires expansion of capabilities through the involvement of specialized firms (Baldwin and Clark, 2000). While an ecosystem may naturally expand as opportunities are recognized (Sahal, 1981; Arthur, 2009), 3D Systems' acquisition strategy suggests an attempt to maintain control of the growing ecosystem.

For Stratasys, a key event was the launch of their Genisys printer in 1996. This product was based on technology acquired from IBM in order to resolve a potential patent infringement and proved the catalyst for several further products in the following years. Stratasys also grew through several strategic acquisitions that expanded its scope. Key among these was the merger with Objet in 2012, which added material jetting technology to the previous focus on extrusion products. The two firms had previously cooperated through a distribution arrangement. Stratasys also co-operated with other firms, for example producing Hewlett-Packard (HP) branded products and relying on Ricoh for modules for its own Objet range of printers. As in the case of 3D Systems, this co-operation demonstrates an effort to guide the growth of the 3DP ecosystem by connecting with other firms: 
"...we collaborate with strategic partners in our ecosystem to streamline the integration of $3 D$ printing solutions into the business processes of our customers." (Stratasys, 2014, p33)

There may, however, be unintended consequences of bringing potential competitors into the ecosystem. Ricoh entered the 3DP ecosystem in 2000 as a supplier to Stratasys. According to an ongoing agreement, Ricoh provided "print heads and associated electronic components... with a non-transferable, non-exclusive right to assemble, use and sell the Ricoh Products under Ricoh's patent rights and trade secrets" (Stratasys, 2013). Modules used in Ricoh's 2D inkjet printers are used to achieve a similar function in 3DP - the print head sprays a photo-sensitive liquid polymer, which is then hardened by a light source. Whereas Ricoh plays a key role in the $2 \mathrm{D}$ printing ecosystem, its role in 3DP, was initially very limited. Later development activity saw this position change. The ecosystem began to grow through the ecosystem leaders' collaborations with other firms, as well as new firms finding opportunities. With this proliferation of ecosystem actors, the next phase is one of internal disruption in which early players seek to defend their position as ecosystem leaders while other actors create opportunities that might lead to disruption.

\subsection{Internal dismption}

The next phase sees 3D Systems, and Stratasys explicitly use the term ecosystem as they describe the comprehensive range of capabilities they control and the solutions they offer.

"We are pursuing a strategy focused on offering a comprehensive ecosystem... We are focused on innovation and new products to drive expansion into 3D production through improving durability, reliability, repeatability and total cost of operations of 3D printing solutions. ”(3D Systems, 2017, 28)

"Integrated solutions offering/ecosystem. We provide an integrated solutions offering that includes compatible products and services that are designed to meet the full gamut of our clients' needs in an efficient manner, consisting of a broad range of systems, consumables and services" (Stratasys, 2015, 33).

The acquisition programs initiated in the previous phase created the foundation for these firms to provide a broad range of offerings, including on-demand printing services and installation of customized printers. The need for these services may be observed by examining the sales revenues shown in Appendix 2. Three features of these statistics are particularly notable. Firstly, the growth in revenues between 2009 and 2014 as the maturity and availability of technologies helped increase demand for 3DP products, with 3D 
Systems and Stratasys benefiting. While product sales have declined since 2014, service revenues continue to grow and show potential to become larger. This is a typical feature of markets in which a large installed base means less scope for new product sales (Beltagui, 2018). It also demonstrates the growth of the ecosystem in terms of modular innovations in supporting services. Finally, the fall in revenues in the two firms demonstrates growing competition within the ecosystem as other firms, including collaborators that challenge their positions, enter the ecosystem. For example, Ricoh acted as a key supplier, and HP provided a distribution channel for Stratasys in the previous phase, whereas in this phase, both compete directly with Stratasys.

Ricoh's technological capabilities, seen through patent activity, lie in optical technologies (e.g. in the US patent classification G03G_Electrography and electrophotography) and others used in office equipment such as copiers, fax machines and projectors. Ricoh's competitors are traditionally "other large manufacturers and distributors of office equipment" (Ricoh, 2011, p.4) but the firm recognizes that "as digital and other new technology develops... Ricoh may find itself competing with new competitors that develop such new technologies... it is possible that new competitors or alliances among existing and new competitors may emerge and rapidly acquire significant market share" (p4). The response to this threat of disruption is partly an aggressive attempt to be similarly disruptive in other ecosystems. Ricoh's growth strategy includes "pursuing possibilities of printing technologies [by transferring these technologies from] 'display printing' to 'applied printing' [including 3DP in manufacturing, electronics and bioprinting applications]"s.

Ricoh launched a 3DP business division in September 2014, but patenting activity in the previous decade demonstrates the effort required to implement their growth strategy. Ricoh's first patent in the B33Y classification ${ }^{9}$ demonstrates search breadth (Katila and Ahuja, 2002), expanding capabilities by drawing on external knowledge. Subsequent patents demonstrate search depth, citing Ricoh's own patents in other classifications. For example, in 2012, Ricoh was granted a patent ${ }^{10}$ related to materials, which cites two

${ }^{8}$ https://www.ricoh.com/-/Media/Ricoh/Sites/com/IR/data/pre/pdf/ir pre2018.pdf, last accessed 5th July 2019.

${ }^{9}$ U.S. Patent 20,050,258,573, Filed May 18, 2004, Granted November 3, 2009.

${ }^{10}$ U.S. Patent 8,192,917, Filed June 28, 2007, Granted June 5, 2012. 
Ricoh patents, in materials and optical recording ${ }^{11}$. Since the patent classification defines the intended function, we can view this as an exaptation (Mastrogiorgio and Gilsing, 2016). The development of a growing patent portfolio supports Ricoh's move from innovating in modules to designing a system architecture. In this case, integrating modules (Fixson and Park, 2008) facilitates a change in ecosystem role. Through extensive R\&D activity, Ricoh moved from a role as a supplier to a manufacturer of 3DP equipment and provider of 3DP services. In doing so, Ricoh posed a disruptive threat to actors in the 3DP ecosystem that mirrored the threat it faced from digital technologies in its own ecosystem.

A similar journey, from 2D to 3DP, has been taken by HP. Its market share of $40 \%$ in $2 \mathrm{D}$ printing ${ }^{12}$, the strength of its patent portfolio and the expiry of core 3DP patents, made it logical and feasible for HP to enter the 3DP ecosystem. First announced in 2014, HP's Fusion Jet technology represented a potential disruption because it did not fit squarely within any of the established 3DP processes (SLA, FDM, etc.). It promised substantial cost savings as well as improvements in production speed and part strength compared with existing polymer 3DP processes. This was later followed by Metal Jet products, offering competition to metal 3DP processes.

HP's entry into the 3DP ecosystem actively disrupted the established actors, including Stratasys and 3D Systems, who offered polymer and metal printing respectively. To achieve this, HP built a system architecture from a range of existing technology modules, but also through co-operation with partners. An example is a B33Y patent ${ }^{13}$ related to fusible water-soluble films for $3 \mathrm{DP}$. This patent cites three of HP's other patents, on inkjet printing inks ${ }^{14}$, macromolecular coatings ${ }^{15}$ and polymers ${ }^{16}$. As with Ricoh, this demonstrates how new functions can be identified for existing knowledge. HP's first involvement in

11 U.S Patent 20,080,092,310 Filed April 27, 2005, Granted Nov 9, 2006. (Material) U.S Patent 20,090,075,014, Filed Sept 13, 2007, Granted March 19, 2009 (Optical Recording)

12 https:/ www.forbes.com/sites/greatspeculations/2014/03/28/why-is-hp-entering-the-3d-printingindustry/\#2050a25c4a09, last accessed 6th July 2019.

13 U.S Patent 6,966,960 Filed May 7, 2003, Granted November 2, 2005

${ }^{14}$ European Patent Office 1,227,136, Filed January, 29, 2001, Granted June, 13, 2007

${ }^{15}$ European Patent Office 1,226,975 Filed January, 29, 2001, Granted August, 23, 2006

16 US Patent 7,365,129 Filed October 14, 2003, Granted April 29, 2008 
3DP came through a branding partnership with Stratasys (Figure 3) but launching its own products put HP in competition with Stratasys.

The leading firms in this phase of the ecosystem's lifecycle have established control over resources through internal development (e.g. Ricoh uses its own distribution network and maintenance services) or acquisitions (e.g. Stratasys and 3D Systems). HP, therefore, looks to co-operate with firms established in other ecosystems, such as BASF, with whom they develop materials for 3DP. Moreover, HP seeks to promote openness, to help its entry and potential to win market share from ecosystem leaders.

"an open ecosystem of industry leaders is critical for greater innovation, breakthrough economics, and faster development of $3 D$ printing materials and applications"17.

This openness creates opportunities for new entrants, leveraging their existing technologies. There is consequent disruption within the ecosystem, but also rapid growth. The next phase could see the early disruptive promise of 3DP technologies realized for the first time as the internal disruption in the ecosystem helps make external disruption feasible.

\subsection{External Dismption}

As noted previously, the aim of disrupting and revolutionizing existing industries was expressed by 3D Systems almost from its inception. However, the subsequent decades of growth have made this aim finally appear more realistic. A vital change can be seen, for example by examining the strategy expressed in 3D Systems' annual reports.

"Ourprincipal competitors are companies that manufacture machines that make, or that use machines to make, models, prototypes, molds and small-volume to medium-volume manufacturing parts... Our competitors also include other suppliers of stereolithography, laser sintering and 3-D printing systems ... such as suppliers of Fused Deposition Modeling” (3D Systems, 2008, p9).

\footnotetext{
${ }^{17}$ https://press.ext.hp.com/us/en/press-releases/2017/hp-accelerates-digital-reinvention-of-manufacturing-industry-wit.html, last accessed 12th January 2019.
} 
"We believe a shift in 3D printing from prototyping to also using additive manufacturing for production is underway. We are focused on innovation and new products to drive expansion into 3D production through improving durability, reliability, repeatability and total cost of operations of 3D printing solutions." (3D Systems, 2017, 28)

Whereas in 2008 competition was restricted to prototyping and suppliers of FDM devices such as Stratasys, in 2017 the ambition has become to disrupt large volume production. Achieving this disruption depends upon incremental innovation, improving the cost and quality of operations. Similarly, Stratasys focuses on "adoption of 3D printing for manufacturing applications.. [by] developing professional services capabilities to enhance our customers' ability to use our solutions" (Stratasys, 2014, p33). This rests in part on technology maturity, but the health of the ecosystem, which has brought a diverse range of new entrants in the previous phase, also contributes. Firms such as HP have similar aims of using 3DP as a means to disrupt manufacturing applications.

"unleashing new possibilities for millions of innovators around the world. No matter your industry, no matter your design complexity, no matter what colors fit your business needs... the new HP Jet Fusion 300 / 500 series gives you the freedom to create brilliant new parts liberated from the constraints of traditional production methods."'s

Perhaps the strongest indication that 3DP can enter mainstream applications comes from the activities of General Electric (GE), which has rapidly taken a key role in the 3DP ecosystem. GE achieved substantial weight-savings by designing a fuel nozzle that integrates around 20 modular components into one, but which had proved impossible to produce by traditional means. The solution was to commission Morris Technologies to create what became one of the first parts produced by 3DP to be approved by the US Federal Aviation Authority. Integrating modules of the artifact profoundly affects the supply chain:

"To make these parts the ordinary way, you typically need 10 to 15 suppliers, you have tolerances, you have nuts, bolts, welds and braces... all of that went away." (Mohammad Ehteshami, GE Additive $\left.{ }^{19}\right)$. ${ }^{18} \mathrm{https} / /$ press.ext.hp.com/us/en/press-releases/2018/hp-accelerates-democratization-of-3d-printing-with-breakthrough-.html
${ }^{19}$ https://www.ge.com/reports/epiphany-disruption-ge-additive-chief-explains-3d-printing-will-upend-manufacturing/ 
The results encouraged GE to acquire Morris Technologies and to set up a 3DP business, GE Additive, in 2016. The fuel nozzle was put into production in the same year (Ford et al., 2016) in a dedicated 3DP factory in Auburn, Alabama, which has produced over 30,000 units, while GE's medical division has 3D printed over 100,000 hip implants. GE has two strategic reasons for its 3DP investment, along with other digital technologies. GE has "the most to gain by building the Industrial Intermet and additive manufacturing and the most to lose by giving it to others." (General Electric, 2016, p.2). Having seen the benefits in its own aviation and medical businesses, GE now recognizes the potential disruption such that this investment protects against disruption as well as hampering competitors who may otherwise take advantage of the technology. At last 3DP emerges as potentially disruptive to incumbents in manufacturing.

\section{Discussion}

This research set out to understand disruptive innovation and digital innovation ecosystems through the lens of exaptation. Based on a longitudinal narrative study of the formation and growth of the 3DP ecosystem, we develop a four-phase process model, shown in Table 1. In this section, we explain the model, before discussing the findings in relation to the research questions and to extant theory.

\subsection{Process Model}

Exaptation plays a vital role in the first phase of the process model, where a new innovation is generated by combining modules from existing artifacts, and in the third phase, where firms specialized in producing these modules find opportunities and applications. The role of the ecosystem is evident in the second phase, where innovators seek to establish the viability of their exaptation-driven innovation by cooperation and the third phase in which modular innovators now compete, as well as co-operate, with ecosystem actors. Disruption is particularly relevant in the third phase, where it mostly occurs internally to the ecosystem, as firms compete to fill niches, but also in the fourth phase, where the exaptationdriven innovation and ecosystem have evolved sufficiently to threaten incumbents in other ecosystems. The connection between exaptation and disruption is characterized by the condition that "not only are the market applications for disruptive technologies unknown at the time of their development, they are unknowable" (Christensen, 1997, p143). This means that the firms involved in the early phases of the ecosystem are unlikely to predict or control the future direction of the technology and the ecosystem. 
Table 1 - Process Model applied to 3DP Ecosystem.

\begin{tabular}{|c|c|c|c|c|}
\hline Phase & 1: Formation & 2: Growth & $\begin{array}{l}\text { 3: Internal } \\
\text { Disruption }\end{array}$ & $\begin{array}{l}\text { 4: External } \\
\text { Disruption }\end{array}$ \\
\hline $\begin{array}{l}\text { Ecosystem } \\
\text { behaviour }\end{array}$ & $\begin{array}{l}\text { Processes invented } \\
\text { and turned into } \\
\text { commercial products } \\
\text { by combining } \\
\text { modules of existing } \\
\text { products through } \\
\text { exaptation-driven } \\
\text { innovation. }\end{array}$ & $\begin{array}{l}\text { Ecosystem leaders } \\
\text { engage specialized } \\
\text { firms to support } \\
\text { development of } \\
\text { technology and } \\
\text { ensure necessary } \\
\text { complements in } \\
\text { search of market } \\
\text { acceptance and } \\
\text { scalability. }\end{array}$ & $\begin{array}{l}\text { Ecosystem leaders } \\
\text { seek control through } \\
\text { mergers and } \\
\text { acquisitions. Growing } \\
\text { market means more } \\
\text { ecosystem niches, } \\
\text { filled by increasingly } \\
\text { larger firms entering } \\
\text { the ecosystem. }\end{array}$ & $\begin{array}{l}\text { Focus on } \\
\text { incremental } \\
\text { improvement as } \\
\text { dominant designs } \\
\text { are established. } \\
\text { Maturity of innovation } \\
\text { makes disruption of } \\
\text { incumbents in other } \\
\text { ecosystems realistic. }\end{array}$ \\
\hline $\begin{array}{l}\text { Notable } \\
\text { Actors }\end{array}$ & $\begin{array}{l}\text { 3D Systems and } \\
\text { Stratasys founded to } \\
\text { commercialise } \\
\text { exaptation-driven } \\
\text { innovations. }\end{array}$ & $\begin{array}{l}\text { 3D Systems and } \\
\text { Stratasys expand } \\
\text { capabilities through } \\
\text { technology } \\
\text { development, co- } \\
\text { operation and } \\
\text { acquisitions. } \\
\text { Ricoh enters the } \\
\text { ecosystem as a } \\
\text { supplier of print } \\
\text { heads to Stratasys. }\end{array}$ & $\begin{array}{l}\text { Ricoh and Hewlett- } \\
\text { Packard use } \\
\text { previous capabilities } \\
\text { to launch products } \\
\text { and services } \\
\text { competing directly } \\
\text { with ecosystem } \\
\text { leaders. }\end{array}$ & $\begin{array}{l}\text { General Electric } \\
\text { applies 3DP to } \\
\text { medical and aviation } \\
\text { applications, creates } \\
\text { 3DP business } \\
\text { through acquisitions } \\
\text { in the ecosystem. }\end{array}$ \\
\hline $\begin{array}{l}\text { Artifact \& } \\
\text { Ecosystem } \\
\text { Design }\end{array}$ & $\begin{array}{l}\text { New artifacts created } \\
\text { by porting modules. }\end{array}$ & $\begin{array}{l}\text { Artifacts developed } \\
\text { by splitting } \\
\text { architecture into } \\
\text { modules to be } \\
\text { developed, creating } \\
\text { niches for } \\
\text { developers. } \\
\text { Ecosystem grows } \\
\text { through entry of } \\
\text { specialized firms to } \\
\text { fill niches. }\end{array}$ & $\begin{array}{l}\text { Artifacts created by } \\
\text { integrating modules, } \\
\text { ecosystem } \\
\text { consolidated through } \\
\text { mergers and } \\
\text { acquisitions. } \\
\text { Competition due to } \\
\text { substituting of artifact } \\
\text { modules and } \\
\text { ecosystem actors. }\end{array}$ & $\begin{array}{l}\text { New applications for } \\
\text { technology by } \\
\text { substituting artifacts } \\
\text { and disrupting } \\
\text { incumbents in other } \\
\text { ecosystems. }\end{array}$ \\
\hline $\begin{array}{l}\text { Co- } \\
\text { opetition }\end{array}$ & Neither & Cooperation & $\begin{array}{l}\text { Competition for } \\
\text { control of ecosystem }\end{array}$ & $\begin{array}{l}\text { Competition between } \\
\text { ecosystems, 3DP } \\
\text { competes with other } \\
\text { technologies. }\end{array}$ \\
\hline
\end{tabular}

The application of this model to 3DP, in Table 1, helps to illustrate how the underlying mechanisms take shape. A crucial connection lies in the symmetry between artifact and ecosystem structure, such that modular operators at the artifact level influence the structure of the ecosystem (Fixson and Park, 2008).

We see exaptation taking shape through modular design, for example splitting artifacts into modules and 
porting some of these modules to create a new artifact that fulfils a different function (Baldwin and Clark, 2000; Andriani and Carignani, 2014). In this case, individual modules (a laser, a glue gun, a motor) may maintain their original functions, but they do so within an artifact that fulfils a new function (building three-dimensional objects). This change of function results in the formation of a new ecosystem, since the producers of the modules (e.g. producers of the liquid furniture coating and producers of electronic components used by Hull in his invention) may have no prior connection to each other or the newly exaptation-driven artifact. Thus, in phase 1, exaptation leads to the formation of the 3DP ecosystem, over the first decade or so, from the end of the 1980s through the 1990s.

Once the modules are ported into the new artifact, i.e. 3D printers made by 3D Systems and Stratasys, it is logical to assume they will be procured from existing producers, such that the suppliers of these modules are effectively invited into the ecosystem. The symmetry between artifact and ecosystem means that, as artifacts evolve, the ecosystem of firms that develop them also evolves in size, form and complexity (Sahal, 1981). The artifacts created in phase 1 are subjected to splitting in phase 2 , to enable specialized firms to develop the modules. In this case, the evolution entails the ecosystem leaders building collaborative networks to support their development of the exaptation-driven innovations that can appeal to the market. Technologies developed by firms such as IBM and Ricoh intersect with the 3DP ecosystem, but in this phase, the strategic opportunities are not central for either firm. Hence IBM agreed to sell to Stratasys, while Ricoh entered the ecosystem as a supplier. Following exaptation-driven innovation, niches are created and can be filled by specialized firms from other ecosystems (Arthur, 2009), such that in phase 2 we observe the growth of the 3DP ecosystem, through the first decade of the $21^{\text {st }}$ century in particular.

Having survived and steadily grown in technological maturity as well as market maturity, the next phase sees 3DP become increasingly mainstream, thereby featuring more clearly in the strategies of firms connected to the ecosystem. Simultaneously, we see the ecosystem leaders seeking to consolidate their position, having grown in size and attempting to control the ecosystem rather than co-operating as before. For example, they launch print-bureau services that place them in competition with their customers who purchase printers to provide such services. Modularity plays a key role, but this time relates to the modules of artifacts and business models as well as actors in the ecosystem. Thus, 3D 
Systems and Stratasys seek to integrate the offerings of their suppliers through mergers (e.g. Stratasys with Objet) and acquisitions.

Meanwhile, firms such as HP and Ricoh move from peripheral to central roles in the 3DP ecosystem by building their own artifacts (and supporting services) by splitting, porting and integrating modules. They find a new function for the technologies, patents and resources (e.g. dealership and service networks) developed in their traditional ecosystems. Survival in this phase of the ecosystem's evolution is incredibly challenging, as can be seen from declining revenues as the number and diversity of competitors grows. While 3DP technologies are mature enough to have an established typology, the entry of firms such as HP and GE, which apply their size advantages to develop and introduce innovations suggests ongoing competition to define dominant designs and consequently, dominance of the ecosystem (Suarez and Utterback, 1995). This phase takes shape during the decade from 2010—as the earliest patents begin to expire. Thus, diversity and openness contribute to internal disruption in the 3DP ecosystem during phase 3.

Finally, our process model predicts that 3DP may later become mainstream, meaning that disruption involving the substitution of established processes with 3DP can take place. This is slowly becoming a realistic proposition as use of 3DP in various industries has increased. And it is greatly accelerated by firms such as HP and GE, who recognize that they face potential disruption from digital technologies and advanced manufacturing technologies. Their entry in the previous phase echoes IBM's entry into the PC ecosystem at the point when technological maturity and market penetration were on the horizon (Moore, 1993). The errors in ecosystem management made by IBM (Fine, 2000) caused it to be disrupted by its own suppliers, as the PC became commoditized. At the low-end, the open-source nature of consumer 3DP (Raasch et al., 2009; West and Kuk, 2016) means the hardware is already commoditized, as 3D Systems found to its cost. At the high-end, the battle for control of the growing 3DP market is closely linked to control of the ecosystem, as the ecosystem leaders see their revenues and profits coming from the supporting services they have built around the artifacts. Thus, we see GE pursuing an acquisitions-led approach, building its 3DP business through the purchase of its suppliers (e.g. Morris Technologies), as well as producers of relevant technology (e.g. Arcam) and materials (e.g. AP\&C, which itself had been 
acquired by Arcam). In phase 4, we can expect to see competition shifting from internal control towards external disruption of other ecosystems.

\subsection{Exaptation and ecosystems}

Considering the relationship between exaptation and ecosystems, we highlight how outcomes can grow from humble beginnings, charting the journey from inventions produced by individuals to billion-dollar firms at the center of an innovation ecosystem. The literature identifies that exaptation can lead to radical innovations (Cattani, 2005) and that it often arises due to serendipitous discoveries by individuals, rather than deliberate strategic effort (Garud et al., 2018). Moreover, it demonstrates that this can occur at the level of a module, which necessitates a period of niche construction, to develop the artifact into a usable product, as observed, for example, with the magnetron and the microwave oven (Andriani and Carignani, 2014). We add to this by demonstrating how ecosystem construction also takes place. This entails the formation of a new ecosystem of co-operating (and potentially competing) firms whose specialized resources are applied to building technical architecture.

The mechanism by which this occurs can be explained with reference to the literature on technology evolution and modular design. Like biological organisms, artifacts can be viewed as modular, hierarchical systems. When the number of modules reaches a certain level, it becomes necessary for multiple actors to design and produce these artifacts (Baldwin and Clark, 2000). Biological systems evolve, while artifacts are innovated through modifications to the modules over time (Darwin, 1859; Basalla, 1989). The supporting ecosystems grow in size and complexity accordingly (Sahal, 1981). In biology, this means niches are available for new entrants into the food chain, while in innovation ecosystems, specialized firms enter the supply chain (Suarez and Utterback, 1995; Fixson and Park, 2008), in both cases resulting in ecosystem growth. The process of niche construction entails "building a technical architecture around the exapted module" (Andriani and Carignani, 2014, p.1613) before bringing the product to market. The new technical architecture creates opportunity niches, i.e. new functions to be identified for existing technologies, (Arthur, 2009), which encourage exaptation (Cattani, 2005).

Thus, the first contribution of this work is to connect the exaptation and innovation ecosystem literatures. We propose that when exaptation-driven innovation results in modules' change of function 
moving them out of their original ecosystems, niche construction at the artifact level is combined with ecosystem construction as collaborators are required to bring the innovation to market.

\subsection{Internal Disruption}

The 3DP ecosystem has increased in diversity as the locus of innovation has moved from the core technology to other layers of the ecosystem (Adner, 2017). For example, 3DP-bureau services are proving to be an important battleground in which technology developers compete with dedicated service providers (Wohlers, 2016; Müller and Karevska, 2016). This fits the general pattern whereby technology development tends to move from the system architecture to modules and competition intensifies between specialized firms innovating these modules (Fixson and Park, 2008; Ho and Lee, 2015). Diversity, competition and indeed disruption, are all indicators of an ecosystem's health, e.g., Costa Rica's diverse ecosystem, rich in flora and fauna, is more resilient than Hawaii's isolated cluster of islands, which few new species can reach (Moore, 1993). The complexity of 3DP technologies and their digital nature create affordances (Autio et al., 2018) for a variety of new entrants and their technologies to compete for ecosystem niches (Nambisan and Baron, 2013). And while initial efforts focus on co-operation to establish an ecosystem, once the ecosystem gains legitimacy, it attracts competitors (Aldrich and Fiol, 1994). As a result, the actions taken to construct the ecosystem also cultivate opportunities for internal disruption within it.

Just as complexity in biological systems leads to self-organization or "design without a Designer" (Simon, 1996, pg.34), an innovation ecosystem can develop a life of its own, beyond the control of the firms within it (Hannan and Freeman, 1984). The emergent nature of ecosystems means actions at one level have systemic impacts. For example, a bird moving slightly to one side, affects those flying around it, leading the whole flock to change direction (Choi et al., 2011). Likewise, decisions made early in the evolution of an innovation have lasting consequences. This includes the decision to co-operate with firms that are likely to disrupt (Ansari et al., 2016), such as Stratasys' decision to bring Ricoh into the 3DP ecosystem or IBM's involvement with Microsoft and Intel. To avoid the disruption IBM faced in the PC ecosystem (Moore, 1993; Fine, 1998), we see attempts to dominate the 3DP ecosystem by merging with promising competitors (Stratasys and Objet) or acquiring suppliers. Simultaneously, the suppliers themselves may seek to expand their roles in the ecosystem. For example, Ricoh changes from supplying 
print-heads to creating 3D printers, drawing on its existing resources and developing new technology, as evidenced by its patenting activity. Internal disruption is made possible by the integration of modules, and by the openness of the ecosystem for actors to exapt technologies they previously developed for other functions (Fixson and Park, 2008; Garud et al., 2018).

Our second contribution rests on investigating disruption in the context of an innovation ecosystem and considering exaptation as the mechanism for ecosystem entry. We propose that, as an innovation ecosystem grows, so does the number and attractiveness of ecosystem niches. The combination of openness to new entrants and the possibility of these entrants to exapt can increase the potential for internal disruption.

\subsection{External Dismption}

Innovation takes time to generate a disruptive impact. One reason for this is that connections to the ecosystem must first be established. This is observed in cases where innovation emerges at the low-end of an established ecosystem (Christensen, 1997) and when digital technology is introduced in co-operation with incumbents in an ecosystem (Ansari et al., 2016). This is also true of 3DP, which has become embedded in the hearing aid and dental implant ecosystems through co-operation between 3DP producers and ecosystem leaders (D’Aveni, 2015; Sandström, 2016). Incumbents are disrupted when they fail to detect that their ecosystem role may be better filled by an entrant (Ho and Lee, 2015), which is possible due to the inherent property of substitution in ecosystems and their modules (Sahal, 1981). But this substitution is not possible without an established ecosystem. Exaptation-driven innovations can be disruptive (Garud et al., 2016), but their disruptive potential is often realized only when a suitable ecosystem is present. Thus, Vestas succeeded where US wind energy firms failed due to Danish government support in cultivating an ecosystem (Garud et al., 2018). This support led to exaptations such as repurposing resources for boat hulls to produce turbine blades. Similarly, Amazon's Kindle ebook reader succeeded where other products based on the same eInk technology in Japan failed (Parry and Kawakami, 2006). The eInk technology can be considered an example of exaptation, which was used by different companies, but Amazon succeeded by cultivating an ecosystem - it offered around 9 times as many books as Sony, due to differences in agreements with book publishers. Ebook readers such as Kindle are potentially disruptive to traditional book publishers, even if ebooks have not replaced printed 
ones. The disruptive threat can be avoided if the threat is recognized and acted upon (Ansari and Krop, 2012; Adner and Kapoor, 2016). Conversely, in this research we see the potential victims of disruption, such as HP and GE, joining the 3DP ecosystem to profit from and defend against what has now become apparent to these firms as a disruption.

3DP has had a disruptive effect within the hearing aid ecosystem, in which firms have either moved to 3DP for producing external casing or gone out of business (D'Aveni, 2015). Despite this, the market leaders have not faced collapse, instead seeing their position maintained or enhanced (Sandström, 2016). For suppliers of hearing aid casings, 3DP is competence-destroying and disruptive, whereas producers of internal electronic components may find 3DP competence-enhancing. Predictions that 3DP will have a disruptive impact on other ecosystems require some precision. It is unlikely that entire ecosystems will be replaced, but more likely that individual niches will be threatened. For example, as the speed, cost and volume of 3DP processes continue to improve, the niches occupied by injection molding firms may be threatened. Injection molding remains more economical for large volumes, but tooling remains prohibitively expensive, creating the opportunity for disruption.

Our third contribution is derived from considering how an ecosystem supports the disruptive potential of exaptation-driven innovation. We propose that the ecosystem must evolve sufficiently to allow an exaptation-driven innovation to achieve external dismption of incumbents in other ecosystems.

\section{Implications and Limitations}

\subsection{Implications for theory}

We contribute to theory at the intersection between exaptation (Andriani and Carignani, 2014; Garud et al., 2016, 2018), innovation ecosystems (Moore, 1996; Iansiti and Levien, 2004; Ansari et al., 2016; Adner et al., 2017) and disruptive innovation (Christensen 1997). The innovation literature shows that technologies are systems of modular components (Baldwin and Clark, 2000) that evolve (Sahal, 1981; Basalla, 1989) through the transfer of modules from one system to another (Arthur, 2009), which is understood in the concepts of niche construction and modular exaptation (Andriani and Carignani, 2014). The critical role of the ecosystem is implied (Garud et al., 2018), but not explicitly mentioned or investigated in the exaptation literature. Meanwhile, the disruptive innovation literature deals with 
different generations of disruptive innovations within ecosystems (Christensen, 1997; Adner and Kapoor, 2010, 2016), and the co-opetitive dynamics between incumbents and entrants into established ecosystems (Ansari et al., 2016). Yet it says little about the subject of ecosystem formation and growth. Our research addresses these gaps by connecting the three literatures.

This research makes three contributions to literature. Firstly, the symmetry between artifact and system leads to the proposition that niche construction of an exapted module is accompanied by ecosystem construction. Secondly, the co-opetitive dynamics within the ecosystem, caused by new entrants competing for niches leads to the proposition that ecosystem evolution entails internal dismption. Thirdly, the evidence of potential to disrupt established ecosystems leads to the proposition that external dismption demands a sufficiently evolved ecosystem in support of exaptation-driven innovation.

\subsection{Implications for practice}

The terms disruptive, digital and ecosystem are hyperbolically used to describe new innovations, but what these terms mean in practice and how to respond to them is unclear. Studying the formation of the ecosystem around 3DP—a set of digital production technologies—helps to illustrate some of the opportunities and threats managers should be aware of. Technologies increasingly combine physical and digital aspects, making them closely connected elements of increasingly complex innovation ecosystems.

Ecosystems are recognized as a rich source of opportunity for entrepreneurs, but part of the challenge is that regardless of their starting position, firms entering into a new ecosystem may have a less central role and hence must balance the objectives of the ecosystem with their own (Nambisan and Baron, 2013; Autio et al., 2018). Managers must take a broad perspective in recognizing the sources of threats, which come from both 'big fish' and 'little fish', both inside and outside the ecosystem. By cultivating an ecosystem, either through attempts to dominate or support others, they create more attractive propositions for larger firms from outside of the ecosystem.

Modular exaptation provides a useful lens through which to view disruptive innovations. For example, Andriani and Carignani (2014) describe how exaptation led to the development of the microwave oven following the identification of a component in radar equipment that could melt an engineer's candy bar. They note, however, that it took two decades to gain popularity and probably longer before the 
microwave oven became disruptive to more traditional cooking appliances. The reason disruptive innovations are so threatening is precisely because they emerge from unexpected directions. Taking an ecosystem perspective would identify the microwave oven as a source of disruption and innovation for other services, for example, food producers could create ready meals, which in turn affects demand for fast-food restaurants. Recognizing that radar equipment producers present a disruptive challenge for restaurants, forty years ahead, would not have been straightforward. Yet, this example illustrates how the complexity of ecosystems creates opportunities and threats from an almost infinite number of sources. The first step, however, is to consider that these challenges come from outside of the current market or industry (Moore, 1996) and that the digital nature of future technologies only widens the scope of ecosystems and sources of disruption.

\subsection{Implications for policy}

Policymakers see ecosystems as the route to supporting national, regional and local innovation (Clarysse et al., 2014) so understanding ecosystems is an important concern for policy. One issue is where to invest resources. Ecosystem leaders would be the best choice according to previous literature (Iansiti and Levien, 2004; Gawer and Cusumano, 2014), but ecosystem leaders, as illustrated in our research, seek to maintain their position of strength, which may involve striving for domination (Fixson and Park, 2008). This is partly because their emphasis changes as they become the leaders, from more exploratory behavior, making use of available resources, to seeking sustained growth, to satisfy shareholders. An alternative for policymakers would be to see ecosystems as a source of opportunities through modular exaptation. The cases investigated in this study demonstrate how existing firms find new narratives (Garud et al., 2016), adapting and building on their capabilities to create new innovations. Supporting openness, for example, encouraging information sharing or at least helping to make the connections between modules and supporting services more accessible, would support the growth of an ecosystem. Policies aimed at supporting firms to find new markets for their existing offerings or to work together to repurpose their capabilities might help localized entrepreneurial ecosystems that take advantage of new technologies such as 3DP.

The exaptation perspective helps to illustrate how unexpected entrants may thrive and suggests that policymakers should examine existing innovations that can be repurposed. Examples of disruptive 
innovation can be considered in terms of the supporting role of the ecosystem. For example, the disruptive potential of wind turbines on traditional energy generation has benefited from exaptation (Garud et al., 2018), which in turn was enabled by suitable incentives and institutional support from public and private sources (Garud and Karnøe, 2003).

Policymakers should also identify barriers to exaptation, for example, Andriani and Carignani (2014) highlight patents as one. They point to the impossibility of knowing all possible uses for an innovation when it is first created, meaning that patents can prevent others from identifying a new function, e.g. chemicals firms find their inert gases in demand for metal 3DP, but their patents may restrict innovation. Meanwhile, the patenting activity of firms such as Ricoh and HP suggests the considerable R\&D investment required for ecosystem entry through exaptation. The recent growth in adoption of 3DP has been in large part due to patent expiry, which has created opportunities for entrepreneurs to create and commercialise new products. The narratives of 3D Systems and Stratasys demonstrate how supporting entrepreneurs to innovate through exaptation may, in the long term, lead to disruptive innovation ecosystems.

\subsection{Limitations and future research}

A number of limitations arise from the methods and scope of the research, which offer opportunities for future research. Firstly, while the narratives uncover the mechanisms by which 3DP may lead to disruption of established systems, it should be noted that the final phase of the process model remains speculative and that experts differ on whether 3DP or the 3DP ecosystem, has yet demonstrated disruption (e.g. Sandström, 2016). The process outlined in the model is an ongoing one, and a follow-up study could revisit the assumptions and predictions of disruption. In particular, while evidence is presented in support of the first phases of the model, phase four is largely speculative and relies on predictions or espoused strategies. Research on disruptive innovation (Adner and Kapoor, 2010; 2016) has benefited from the approach of updating and revisiting the same dataset, following the evolution of one ecosystem, and 3DP as a context would undoubtedly benefit from the same, as the technologies and applications emerge. Therefore, further studies should seek to establish whether and when 3DP can be considered a disruptive innovation as well as testing the process model. Disruptive innovations are often 
identified only after they have caused disruption, whereas 3DP offers a valuable research subject since it is almost widely considered to be a disruptive innovation waiting for a killer application.

Secondly, this study takes a selective view of a small number of firms, which helped the 3DP ecosystem form. Secondary data, available in the public domain, were used to understand these firms and their actions. The lack of primary data collection, such as interviews with decision makers can be viewed as a weakness. Meanwhile, using a varied range of sources helps to avoid unconscious biases related to recall or social desirability, which can call into question the validity of interviews. As the availability of data has increased, so has the innovative use of such data in research (Koppman and Leahey, 2019). The present study therefore follows the increasingly common approach of using data from publicly available sources (e.g,Turnheim and Geels, 2019; Franzoni and Sauermann (2014).

Thirdly, the narrative method is, by its nature, interpretive in its approach. Narratives are constructed, or enacted, in a process of sense-making, rather than describing a set of events (Pentland, 1999; Garud et al., 2016). This means that narratives may privilege one interpretation while suppressing others (Brown, 1998). We used quotations from a number of sources to make sense of events and to provide a structure that connects the events. Nonetheless, we acknowledge that alternative perspectives and ways of seeing the events are possible. In particular, we present the invention of 3DP technologies as illustrative of modular exaptation and seek to identify serendipity and functional change in the accounts of their invention. We acknowledge that alternative perspectives may be used to argue otherwise. Despite this possibility, we believe the process model, connecting exaptation, ecosystem formation and disruption, is theoretically valid.

\section{References}

3D Systems Corporation (2008) Annual Report on Form 10-K for the Year Ended December 31, 2008. Available at [https://uk.3dsystems.com/sites/default/files/2017-02/3DSystems-2008AnnualReport.pdf], last accessed $18^{\text {th }}$ June, 2018.

3D Systems Corporation (2017) Annual Report on Form 10-K for the Year Ended December 31, 2017. Available at https://uk.3dsystems.com/sites/default/files/2018-03/3d-systems-2017-form-10k_0.pdf], last accessed $18^{\text {th }}$ June, 2018.

Adner, R. 2017. Ecosystem as structure: An actionable construct for strategy. Journal of Management, 43(1), $39-58$. 
Adner, R., Kapoor, R. 2010. Value creation in innovation ecosystems: How the structure of technological interdependence affects firm performance in new technology generations. Strategic Management Journal, 31(3), 306-333.

Adner, R., Kapoor, R. 2016. Innovation ecosystems and the pace of substitution: Re-examining technology S-curves. Strategic Management Journal, 37(4), 625-648.

Aldrich, H.E. and Fiol, C.M. 1994. 'Fools rush in? The institutional context of industry creation'. Academy of Management Review, 19(4), 645-70.

Andriani, P. and Cattani, G., 2016. Exaptation as source of creativity, innovation, and diversity: Introduction to the special section. Industrial and Corporate Change, 25(1), 115-131.

Andriani, P. and Carignani, G., 2014. Modular exaptation: a missing link in the synthesis of artificial form. Research Policy, 43(9), 1608-1620.

Andriani, P., Ali, A. and Mastrogiorgio, M., 2017. Measuring exaptation and its impact on innovation, search, and problem solving. Organization Science, 28(2), 320-338.

Andriani, P. and Cohen, J., 2013. From exaptation to radical niche construction in biological and technological complex systems. Complexity, 18(5), pp.7-14.

Ansari, S., Krop, P. 2012. Incumbent performance in the face of a radical innovation: Towards a framework for incumbent challenger dynamics. Research Policy, 41(8), 1357-1374.

Ansari, S. S., Garud, R., Kumaraswamy, A. 2016. The disruptor's dilemma: TiVo and the U.S. television ecosystem. Strategic Management Journal, 37(9), 1829-1853.

Arthur, W.B. 2009. The nature of technology. What it is and how it evolves. Allen Lane Books: London.

Autio E, Thomas, L.D.W. 2014. Innovation Ecosystems, in Dodgson,M., Gann, D.M., Phillips, N. (eds) The Oxford handbook of innovation management, pp.204-228, Oxford University Press: Oxford.

Autio, E., Nambisan, S., Thomas L.D.W, Wright, M. 2018. Digital affordances, spatial affordances, and the genesis of entrepreneurial ecosystems, Strategic Entrepreneurship Journal, 12, 72-95.

Baldwin, C.Y., Clark, K.B. 2000. Design rules: The power of modularity (Vol. 1). MIT press: Cambridge, MA.

Bandyopadhay, A., Gualtieri, T. P., \& Bose, S. 2015. Global Engineering and Additive Manufacturing. In Bandyopadhay,A. and Bose,S. (Eds.), Additive Manufacturing. CRC Press: Boca Raton, FL.

Barnatt, C. 2016. 3D-Printing, 3rd edition, CreateSpace: Charleston, SC.

Basalla, G. 1989. The evolution of technology. Cambridge University Press: Cambridge.

Beltagui, A. 2018. A design-thinking perspective on capability development: the case of new product development for a service business model. International Journal of Operations \& Production Management, 38(4), 1041-1060.

Bonifati, G. 2010. 'More is different', exaptation and uncertainty: three foundational concepts for a complexity theory of innovation. Economics of Innovation and New Technology, 19(8), 743-760.

Brown, A.D., 1998. Narrative, politics and legitimacy in an IT implementation. Journal of Management Studies, 35(1), 35-58.

Candi, $\mathrm{M}$ and Beltagui, A.2019. Effective use of 3D printing in the innovation process" Technovation, 8081, 63-73.

Carignani, G., Cattani, G. and Zaina, G., 2019. Evolutionary chimeras: a Woesian perspective of radical innovation. Industrial and Corporate Change, article in press.

Cattani, G., 2005. Preadaptation, firm heterogeneity, and technological performance: a study on the evolution of fiber optics, 1970-1995. Organization Science, 16(6), 563-580. 
Ching, K. 2016. Exaptation dynamics and entrepreneurial performance: evidence from the Internet video industry. Industrial and Corporate Change, 25(1), 181-198.

Choi, T. Y., Dooley, K. J., Rungtusanatham, M. 2001. Supply networks and complex adaptive systems: Control versus emergence. Journal of Operations Management, 19(3), 351-366.

Christensen, C. M. 1997. Innovator's Dilemma: When new technologies cause great firms to fail. Harvard Business School Press, Boston, MA.

Clarysse, B., Wright, M., Bruneel, J., Mahajan, A., 2014. Creating value in ecosystems: Crossing the chasm between knowledge and business ecosystems. Research Policy, 43(7), 1164-1176.

Cozzolino, A., Verona, G. and Rothaermel, F.T., 2018. Unpacking the disruption process: New technology, business models, and incumbent adaptation. Journal of Management Studies, 55(7), pp.11661202.

Darwin, C. 1859. "On the Origin of Species By Means of Natural Selection, or, the Preservation of Favoured Races in the Struggle for Life", Public Domain Books. Kindle Edition.

D’Aveni, R. 2015. The 3-D Printing Revolution. Harvard Business Review, 93(3), 41-48.

Dedehayir, O., Mäkinen, S.J., Ortt, J.R. 2016. Roles during innovation ecosystem genesis: a literature review. Technological Forecasting and Social Change. DOI:10.1016/j.techfore.2016.11.028

Dew, N. 2007. Pre-adaptation, exaptation and technology speciation: a comment on Cattani (2006). Industrial and Corporate Change, 16(1), 155-160.

Dew, N., Sarasvathy, S.D. 2016. Exaptation and niche construction: behavioral insights for an evolutionary theory. Industrial and Corporate Change, 25(1), 167-179.

Economist, the. 2015. Does Deutschland do digital? 21st November, available online at [https://www.economist.com/business/2015/11/21/does-deutschland-do-digital], last accessed 9th July 2019.

Estes, J.A., Palmisano, J.F. 1974. Sea otters: their role in structuring nearshore communities. Science, 185, 1058-1060.

Fine, C.H. 1998. Clockspeed: winning industry control in the age of temporary advantage. Perseus Books, Reading, MA.

Fixson, S.K. and Lee, W.H. 2012. Shifting grounds: how industry emergence changes the effectiveness of knowledge creation strategies - the case of the US automotive airbag industry. Technology Analysis \& Strategic Management, 24(1), 1-19.

Fixson, S. K., Park, J. K. 2008. The power of integrality: Linkages between product architecture, innovation, and industry structure. Research Policy, 37(8), 1296-1316.

Ford, S., Mortara, L. and Minshall, T. 2016. The Emergence of Additive Manufacturing, Technological Forecasting \& Social Change, 102(1), 156-159.

Franzoni, C., Sauermann, H., 2014. Crowd science: The organization of scientific research in open collaborative projects. Research Policy, 43(1), 1-20.

Gabriel, Y. (2000), Storytelling in organizations: facts, fictions, and fantasies, Oxford University Press, Oxford.

Garud, R., Karnøe, P.J. 2003. Path Creation as a Process of Mindful Deviation, in Garud, R., Karnøe,P (eds) Path dependence and creation, Psychology Press: Hove.

Garud, R., Gehman, J. and Giuliani, A.P., 2014. Contextualizing entrepreneurial innovation: A narrative perspective. Research Policy, 43(7), 1177-1188.

Garud, R., Gehman, J. and Giuliani, A.P., 2016. Technological exaptation: a narrative approach. Industrial and Corporate Change, 25(1), 149-166. 
Garud, R., Gehman, J. and Giuliani, A.P. 2018. Serendipity arrangements for exapting science-based innovations. Academy of Management Perspectives, 32(1), 125-140.

Gawer, A., Cusumano, M. A. 2014. Industry platforms and ecosystem innovation. Journal of Product Innovation Management, 31(3), 417-433.

Gawer, A., Henderson, R. 2007. Platform owner entry and innovation in complementary markets: Evidence from Intel. Journal of Economics and Management Strategy, 16(1), 1-34.

General Electric Company. 2016. Leading a digital industrial era, 2016 Annual Report, General Electric Company: Boston, MA.

Goldenfeld, N. and Woese, C., 2007. Biology's next revolution. Nature, 445(7126), p.369.

Gould, S.J., Vrba, E.S. 1982. Exaptation-a missing term in the science of form. Paleobiology, 8(1), 4-15.

Hannan, M.T., Freeman, J. 1977. The population ecology of organizations. American Journal of Sociology, 82(5), 929-964.

Hannan, M.T., Freeman, J., 1984. Structural inertia and organizational change. American Sociological Review, 49(2), 149-164.

Ho, J. C., Lee, C.-S. 2015. A typology of technological change: Technological paradigm theory with validation and generalization from case studies. Technological Forecasting and Social Change, 97, 128-139.

Iansiti, M., Levien, R. 2004, March. Strategy as Ecology. Harvard Business Review., 82(3), 68-81.

Jick, T.D. 1979. Mixing qualitative and quantitative methods: Triangulation in action. Administrative science quarterly, 24(4),602-611.

Kapoor, R., 2013. Persistence of integration in the face of specialization: How firms navigated the winds of disintegration and shaped the architecture of the semiconductor industry. Organization Science, 24(4), 1195-1213.

Katila, R., Ahuja, G. 2002. Something old, something new: A longitudinal study of search behavior and new product introduction. Academy of Management Journal, 45(6), 1183-1194.

Keller, A., Hüsig, S. 2009. Ex ante identification of disruptive innovations in the software industry applied to web applications: The case of Microsoft's vs. Google's office applications. Technological Forecasting and Social Change, 76(8), 1044-1054.

Koppman, S. and Leahey, E., 2019. Who moves to the methodological edge? Factors that encourage scientists to use unconventional methods. Research Policy, p.103807.

Kozinets, R. V. (2002). The field behind the screen: Using netnography for marketing research in online communities. Journal of Marketing Research, 39(1), 61-72.

Lee, K., Malerba, F. 2017. Catch-up cycles and changes in industrial leadership: Windows of opportunity and responses of firms and countries in the evolution of sectoral systems. Research Policy, 46(2), 338351.

Levin S.A. 1998. Ecosystems and the biosphere as Complex Adaptive Systems. Ecosystems, 1, 431-436.

Li, J.F., Garnsey, E. 2014. Policy-driven ecosystems for new vaccine development. Technovation, 34(12), 762-772.

Lucas, H. C., Goh, J. M. 2009. Disruptive technology: How Kodak missed the digital photography revolution. Journal of Strategic Information Systems, 18(1), 46-55.

Mastrogiorgio, M., Gilsing, V., 2016. Innovation through exaptation and its determinants: The role of technological complexity, analogy making \& patent scope. Research Policy, 45(7), 1419-1435.

Moore, J.F. 1993. Predators and prey: a new ecology of competition. Harvard Business Review, 71(3), 75-86. 
Moore, J.F. 1996.The death of competition: leadership and strategy in the age of business ecosystems. Harper Business: New York,NY.

Müller, A, Karevska, S. 2016. How will 3D printing make your company the strongest link in the value chain? Ernst and Young: Mannheim, Germany.

Nambisan, S., Baron, R.A., 2013. Entrepreneurship in innovation ecosystems: entrepreneurs' selfregulatory processes and their implications for new venture success. Entrepreneurship Theory and Practice, 37(5), 1071-1097.

Nambisan, S. 2017. Digital entrepreneurship: Toward a digital technology perspective of entrepreneurship, Entrepreneurship Theory and Practice, 41(6), 1029-1055.

Narayanan, V.K., Colwell, K., Douglas, F.K. 2009. Building organizational and scientific platforms in the pharmaceutical industry: a process perspective on the development of dynamic capabilities, British Journal of Management, 20(S1), S25-S40.

Parry, M. E., Kawakami, T. 2016. The Encroachment Speed of Potentially Disruptive Innovations with Indirect Network Externalities: The Case of E-Readers. Journal of Product Innovation Management, 34(2): 141-158.

Pentland, B.T. 1999. Building process theory with narrative: from description to explanation, Academy of Management Review, 24(4), 711-724.

Petrovic, V., Vicente Haro Gonzalez, J., Jorda Ferrando, O., Delgado Gordillo, J., Ramon Blasco Puchades, J., Portoles Grinan, L. 2011. Additive layered manufacturing: sectors of industrial application shown through case studies. International Journal of Production Research, 49(4), 1061-1079.

Piller, F. T., Weller, C., Kleer, R. 2015. Business Models with Additive Business Models with Additive Manufacturing-Opportunities and Challenges from the Perspective of Economics and Management. Advances in Production Technology: 39-48.

Ricoh Company Ltd, 2011. Ricoh Group Annual Report 2011, Financial Section. Ricoh Company Ltd., Tokyo: Japan. Available at: [https://www.sec.gov/Archives/edgar/data/317891/000119312511178081/d20f.htm], last accessed, $6^{\text {th }}$ July 2019

Rüßmann, M., Lorenz, M., Gerbert, P., Waldner, M., Justus, J, Engel, P. Harnisch, M. 2015. Industry 4.0 The future of productivity and growth in manufacturing industries, Boston Consulting Group: Munich, Germany.

Sahal, D. 1981. Patterns of technological innovation. Addison-Wesley: Reading, MA.

Sandström, C. G. 2016. The non-disruptive emergence of an ecosystem for 3D Printing - Insights from the hearing aid industry's transition 1989-2008. Technological Forecasting and Social Change, 102, 160-168.

Simon, H.A. 1996. The sciences of the artificial, 2nd ed., MIT Press: Cambridge, MA.

Snihur, Y., Thomas, L.D., Burgelman, R.A. 2018. An ecosystem-level process model of business model disruption: The disruptor's gambit. Journal of Management Studies. 55(7), 1278-1316.

Stratasys Ltd. 2014 Form 20-F, available at [http://investors.stratasys.com/static-files/7a2f0481-768044cb-bc08-17d55d7470c6], last accessed 18 ${ }^{\text {th }}$ June, 2018.

Stratasys Ltd. 2015 Form 20-F, available at [http://investors.stratasys.com/static-files/8e0c37cb-a1bb43f3-b804-21ac183c96b5], last accessed 18 th June, 2018.

Suarez, F.F., Utterback, J.M. 1995. Dominant designs and the survival of firms. Strategic Management Journal, 16(6), 415-430.

Teece, D.J. 2010. Business models, business strategy and innovation. Long Range Planning, 43(2-3), 172194. 
Turnheim, B., and Geels, F.W. 2019. Incumbent actors, guided search paths, and landmark projects in infra-system transitions: Re-thinking Strategic Niche Management with a case study of French tramway diffusion (1971-2016). Research Policy, 48(6), 1412-1428.

United States Patent and Trademark Office. 2017 B33Y, available at [https://www.uspto.gov/web/patents/classification/cpc/pdf/cpc-definition-B33Y.pdf], last accessed, 12th January, 2019.

West, J., Kuk, G. 2016. The complementarity of openness: How MakerBot leveraged Thingiverse in 3D printing. Technological Forecasting and Social Change, 102, 169-181.

Wohlers. 2016. Woblers Report 2016 - 3D Printing and Additive Manufacturing State of the Industry Annual Worldwide Progress Report, Wohlers Associates Inc.: Fort Collins, CO.

Wozniak, S., Smith, G. 2006. iWoz: from computer geek to cult icon: how I invented the personal computer, co-founded Apple, and had fun doing it, W.W.Norton and Co.: New York, NY. 
Appendix 1 - Summary of key details for 3D Systems and Stratasys

\begin{tabular}{|c|c|c|}
\hline & 3D systems & Stratasys \\
\hline Founding date & 1986 & 1989 \\
\hline $\begin{array}{l}\text { First patented } \\
\text { technology }\end{array}$ & $\begin{array}{l}\text { "Apparatus for Production of } \\
\text { Three-dimensional Objects by } \\
\text { Stereolithography" Patent } \\
\text { 4575330A (1986) }\end{array}$ & $\begin{array}{l}\text { "Apparatus and Method for Creating } \\
\text { Three-dimensional Objects" } \\
\text { Patent } 5121329 \text { (1992) }\end{array}$ \\
\hline IPO date & June 3,2011 & October 20, 1994 \\
\hline Headquarters & $\begin{array}{l}\text { Rock Hill, South Carolina, United } \\
\text { States }\end{array}$ & $\begin{array}{l}\text { Eden Prairie, Minnesota, United States } \\
\text { / Rehovot, Israel }\end{array}$ \\
\hline Founder & Chuck Hull (currently CTO) & S. Scott Crump (currently Chairman) \\
\hline CEO & Vyomesh Joshi (4 Apr 2016) & Ilan Levin (1 Jul 2016) \\
\hline $\begin{array}{l}\text { Key Mergers \& } \\
\text { Acquisitions }\end{array}$ & $\begin{array}{l}2014 \text { Cimatron }(\$ 97 \mathrm{~m})- \\
\text { Design software } \\
2014 \text { Simbionix }(\$ 120 \mathrm{~m})- \\
\text { Medical simulation and training } \\
\text { solutions } \\
2013 \text { Xerox's 3DP assets } \\
(\$ 32.5 \mathrm{~m}) \\
2009 \text { Acu-Cast Technologies } \\
\text { (undisclosed) - custom } \\
\text { manufacturing } \\
2001 \text { DTM }(\$ 45 \mathrm{~m})-3 D \\
\text { Printing }\end{array}$ & $\begin{array}{l}2015 \text { Econolyst (undisclosed) - } \\
\text { Strategic consultancy } \\
2014 \text { GrabCAD ( } \$ 100 \mathrm{~m}) \text { - Design } \\
\text { software } \\
2014 \text { Solid Concepts \& Harvest Tech. } \\
\text { (undisclosed) - custom manufacturing } \\
2012 \text { Objet ( } \$ 634 \mathrm{~m}) \text { - 3D printing, } \\
\text { resulted in creation of Stratasys Inc. } \\
2011 \text { Solidscape - ( } \$ 38 \mathrm{~m}) \text { Aerospace } \\
\text { Manufacturing } \\
1995 \text { IBM's 3DP assets }(\$ 0.5 \mathrm{~m} \text { and } \\
\text { 0.5m shares in Stratasys) }\end{array}$ \\
\hline Technologies & $\begin{array}{l}\text { Stereolithography (SLA), } \\
\text { Selective Laser Sintering (SLS), } \\
\text { Color-Jet Printing (CJP), } \\
\text { Multi-Jet Printing (MJP), } \\
\text { Direct Metal Printing (DMP) }\end{array}$ & $\begin{array}{l}\text { PolyJet, } \\
\text { Fused Deposition Modelling (FDM) }\end{array}$ \\
\hline Revenue $^{1}$ & $\$ 633$ million & \$696 million \\
\hline $\begin{array}{l}\text { Market } \\
\text { Capitalization }^{2}\end{array}$ & $\$ 1.022$ billion & $\$ 1.155$ billion \\
\hline $\begin{array}{l}\text { R\&D as a } \% \text { of } \\
\text { revenue }\end{array}$ & $3.4 \%$ & $3.5 \%$ \\
\hline
\end{tabular}


Appendix 2 - 3D Systems' and Stratasys' sales revenues 2009-2017 in thousands of USD, based on annual reports.

Sales revenues 2009-2017

$\$ 700,000$ (USD in thousands. Source: annual reports)

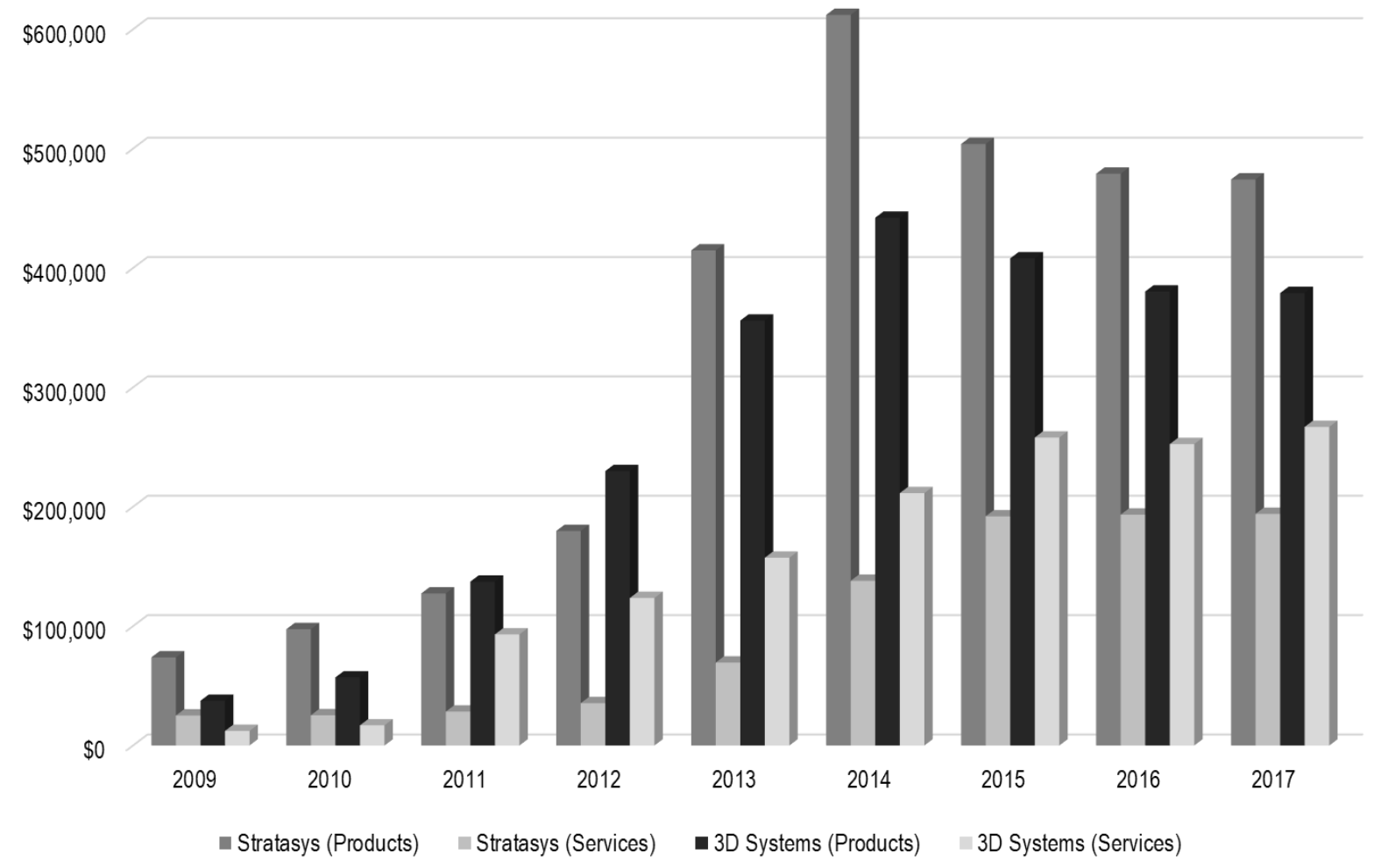

